\title{
Reading fluency and statistical learning across modalities and domains: online and offline
}

measures

Ágnes Lukács ${ }^{1,2}$, Dorottya Dobó ${ }^{1,2}$, Ágnes Szőllősi ${ }^{1,3}$, Kornél Németh $^{1,2}$, Krisztina Sára Lukics $^{1,2}$

${ }^{1}$ Department of Cognitive Science, Budapest University of Technology and Economics

Address: Budapest, Egry József utca 1., H-1111, Hungary

${ }^{2}$ MTA-BME Momentum Language Acquisition Research Group, Eötvös Loránd Research

Network (ELKH), Budapest, Hungary

Address: Budapest, Egry József utca 1., H-1111, Hungary

${ }^{3}$ Institute of Cognitive Neuroscience and Psychology, Eötvös Loránd Research Network

(ELKH), Budapest, Hungary

Address: Budapest, Magyar tudósok körútja 2., H-1117, Hungary

Author e-mail addresses:

Á. Lukács (corresponding author): lukacs.agnes@ttk.bme.hu

D. Dobó: dobo.dorottya@ttk.bme.hu

Á. Szőllősi: szollosi.agnes@ttk.bme.hu

K. Németh: nemeth.kornel@ttk.bme.hu

K. S. Lukics (corresponding author): lukics.krisztina.sara@ttk.bme.hu

Link for stimuli, data, and analysis codes:

https://drive.google.com/drive/folders/1YcQi3mkFr5i1W4xP2YAl53xfuRQwae3t?usp=sharing 


\title{
Highlights
}

- We tested statistical learning in adolescents with different levels of reading fluency.

- Statistical learning was tested in the verbal acoustic and the nonverbal visual domain.

- We used an online target detection task, as well as an offline 2AFC task.

- Online learning measures did not differ as a function of reading capacity.

- The $2 \mathrm{AFC}$ measure differed as a function of reading skill in the verbal acoustic task.

\begin{abstract}
The vulnerability of statistical learning has been demonstrated in reading difficulties in both the visual and acoustic domains. We examined segmentation abilities of adolescents with three different levels of reading fluency in the acoustic verbal and visual nonverbal domains. We applied online target detection tasks, where the extent of learning is reflected in differences between reaction times to predictable versus unpredictable targets. Explicit judgments of well-formedness were also elicited in an offline two-alternative forced choice task. A significant online learning effect was observed in all groups in both domains, and online patterns were similar in participants with low, medium and high reading fluency. On the offline measures, all groups were at chance in the visual, but not the verbal domain. These findings suggest that there is no robust statistical learning impairment associated with reading problems either in the visual or the acoustic domain in adolescents. Results also imply that offline measures may mask learning abilities, and measuring learning online can provide a deeper understanding of the learning process and of its potential deficits.
\end{abstract}

\section{Keywords}

reading fluency, acoustic statistical learning, visual statistical learning, online target detection task, two-alternative forced choice (2AFC) task 


\section{Introduction}

As a specific difficulty in learning to read, developmental dyslexia is causal in problems with learning through reading which is central in most school settings. It has recently been suggested that reading problems might also result from deficits in some type of basic learning mechanism (Bogaerts et al., 2021; Nicolson \& Fawcett, 2007, 2011), more specifically from deficits in statistical learning (SL $\left.{ }^{1}\right)$ (e.g., Schmalz, Altoè, \& Mulatti, 2017). SL is the capacity to extract patterns and regularities from environmental stimuli through observation sensitive to frequency distributions and transitional probabilities (Frost, Armstrong, Siegelman, \& Christiansen, 2015). Although the vulnerability of SL has been demonstrated in dyslexia in different domains (e.g., Gabay, Thiessen, \& Holt, 2015; Kahta \& Schiff, 2019; Sigurdardottir et al., 2017; Tong, Leung, \& Tong, 2019; for a meta-analysis, see van Witteloostuijn, Boersma, Wijnen, \& Rispens, 2017) and with diverse methods, the findings are controversial.

In the present study, we aimed at investigating the complex relationship between SL, more specifically statistical segmentation and reading skills. While most previous studies examined segmentation in the acoustic domain in relation with dyslexia, visual segmentation skills, which are also relevant for reading, received less attention. Therefore, our aim was to test and directly compare SL in verbal and visual segmentation tasks. We employed target detection tasks, where the extent of learning is reflected in the differences between reaction times (RT) to predictable versus unpredictable targets. Explicit judgments of well-formedness were also elicited in a twoalternative forced choice (2AFC) task to compare sensitivity of different measures. Since reading difficulties are not exclusive to individuals with dyslexia (i.e., reading skills show considerable variability in the typical population as well), as a methodological novelty, we recruited people

\footnotetext{
${ }^{1}$ SL: statistical learning
} 
with dyslexia for our study, but we did not compare the performance between people living with dyslexia and people with no diagnosis of dyslexia. Instead, to gain better insight into the relationship of SL and reading skills, we compared performance in three groups with three different levels of reading fluency.

\subsection{Developmental Dyslexia and the spectrum of reading skills}

Developmental dyslexia (DD) is a neurodevelopmental disorder involving the selective impairment of reading, which is not caused by reduced intelligence, low socio-economic status or inadequate teaching methods (American Psychiatric Association, 2013). Prevalence estimates vary between 5-17\% in the US (Gabay, Thiessen, \& Holt, 2015; Shaywitz \& Shaywitz, 2007), but they can greatly vary across countries and languages depending on diagnostic criteria and orthography type (see e.g., Landerl, Wimmer \& Frith, 1997; Landerl et al., 2013). At the behavioural level, DD is defined by reading difficulties, explained by a combination of welldocumented deficits in phonological processing difficulties, and lexical retrieval problems and reduced capacity of verbal short term memory (Boada \& Pennington, 2006; Brady, Shankweiler \& Mann, 1983; Bruck, 1992; Ho \& Lai, 1999; Ramus, 2003; Ramus et al., 2003; Snowling \& Melby-Lervåg, 2016; Vellutino, Fletcher, Snowling \& Scanlon, 2004; Wolf \& Bowers, 1999). Reading skills and reading comprehension, however, show considerable variability in the typical population as well (Freed, Hamilton, \& Long, 2017; Just \& Carpenter, 1992; Long \& Freed, 2021; Waters \& Caplan, 1996) and reading difficulties are not exclusive to individuals with dyslexia. They may occur in other neurodevelopmental disorders for different reasons (e.g. in ADHD or ASD; Miller et al., 2013; Nally, Healy, Holloway, \& Lydon, 2018). Low IQ may also be associated with poor reading abilities (in some 'garden variety poor readers'; see e.g., Stanovich, 1988; Stuebing et al, 2002), and other cognitive and socioeconomic factors may also 
contribute to poor reading abilities without the presence of a specific reading disorder (see e.g., Kuppen \& Goswami, 2016; Nigro, Jiménez-Fernández, Simpson \& Defior, 2016). Since poor readers and individuals with dyslexia are not defined based on the severity, but rather on the specificity of the reading difficulty, reading performance in itself is not enough to establish or exclude a dyslexia diagnosis. Based on the lack of clear-cut boundaries and the lack of comprehensive standardised diagnostic tools for adolescents in Hungarian, instead of comparing performance between people with and without dyslexia, we divided participants into groups based on their reading fluency. Moreover, since reading skills - as many other skills - can be seen on a spectrum, instead of comparing the performance across two groups (typical readers vs. poor readers), we divided participants into three categories based on reading fluency.

\subsection{Statistical learning in typical and atypical readers}

Statistical learning (SL) is a form of learning through observation sensitive to frequency distributions and transitional probabilities which extracts patterns and regularities from environmental stimuli (Frost et al., 2015). SL is argued to be essential in many areas of cognition across domains and modalities, including discrimination, categorization, segmentation, and prediction (Conway, 2020; Frost et al., 2015). Given the nature and complexity of human languages, statistical learning is suggested to play a key role in the acquisition of many levels of language (Frost et al., 2015; Romberg \& Saffran, 2010; Saffran, 2002): in developing phoneme representations (tuning phoneme representations to the mother tongue), in word segmentation, pairing words and meanings, and in extracting grammatical regularities. Associations between SL and performance on different language tasks have been found including a) speech perception in noise (Conway, Karpicke, \& Pisoni, 2007; Conway, Bauernschmidt, Huang, \& Pisoni, 2010), b) adult natural language ability (Daltrozzo et al., 2017), c) natural language processing in 
infants (Lany, Shoaib, Thompson, \& Graf Estes, 2018), d) syntactic priming effects in preschool children (Kidd, 2012), e) syntax comprehension (Kidd \& Arciuli, 2016; Misyak \& Christiansen, 2012), and f) lexical access (Mainela-Arnold \& Evans, 2014). SL and language processing also show a neural overlap (Christiansen, Conway, \& Onnis, 2012; Morgan-Short et al., 2015; Petersson, Folia, \& Hagoort, 2012). Altogether, the above results suggest that SL shares mechanisms with language processing and language learning on many levels.

The contribution of statistical learning is not restricted to spoken language acquisition and use. It may have an impact on learning to read both in direct and indirect ways: 1) in the extraction of orthographic regularities, 2) in the acquisition of orthography-phonology correspondences, 3 ) and it can also influence the efficiency of the reading process indirectly through contributing to reading-related skills like word learning and grammar acquisition (Apfelbaum, Hazeltine \& McMurray, 2013; Arciuli, 2018; Arciuli \& Simpson, 2012; Schubert, Cohen, \& Fischer-Baum, 2020; Siegelman et al., 2020; Spencer, Kaschak, Jones \& Lonigan, 2015; Torkildsen, Arciuli, \& Wie, 2019). Correlation studies have already demonstrated important associations between SL and language processing and reading (with accuracy, fluency and decoding, Arciuli, 2018; Nicolson \& Fawcett, 2011) and writing (Nicolson \& Fawcett, 2011) abilities in both children and adults (Torkildsen, Arciuli \& Wie, 2019).

Based on these observations, it is expected that impairments in SL abilities are associated with reading difficulties (Nicolson \& Fawcett, 2011). In line with this hypothesis, statistical learning has been shown to be vulnerable in dyslexia and recent studies have found evidence for the association of SL deficit and reading impairment in DD (Gabay et al., 2015; Kahta \& Schiff, 2019; Tong, Leung \& Tong, 2019). Notably, this association has been mostly confirmed in studies of speakers of languages with opaque orthographies (such as Chinese, Hebrew and 
English), and less is known about this association in languages with transparent orthographies (i.e., orthographies where the correspondence between graphemes and phonemes is close to oneto-one).

In studies investigating people with dyslexia, impairments have been observed in different forms of SL mostly in the visuomotor and visual, but also in the acoustic domain. Motor sequence learning (Gabay, Schiff \& Vakil, 2012; Kelly, Griffith \& Frith, 2002; Stoodley, Ray, Jack \& Stein, 2008; Vicari, Marotta, Menghini, Molinari \& Petrosini, 2003), word segmentation (Gabay et al., 2015; Sigurdardottir et al., 2017; Tong et al., 2019) and artificial grammar learning tasks (Dobó, Lukics, Szőllősi, Németh, \& Lukács, 2021; Kahta \& Schiff, 2016, 2019; Nigro et al., 2016; Pavlidou, Kelly, \& Williams, 2010) have all shown SL deficits in dyslexia. However, results are far from equivocal and methods vary greatly. For example van Witteloostuijn, Boersma, Wijnen, and Rispens (2019) have not found a deficit in SL either in the acoustic or the visual modality in a large sample of Dutch speaking children with DD using three different tasks. As a further example, while meta-analyses show evidence for a deficit in motor sequence learning in the Serial Reaction Time (SRT) task (Lum, Ullman, \& Conti-Ramsden, 2013), evidence for a visual SL deficit is less straightforward. A meta-analysis of visual artificial grammar learning (AGL) studies in dyslexia (van Witteloostuijn et al., 2017) showed deficits in visual AGL in dyslexia, but the authors point out that if publication bias against negative results is taken into account, the effect could be zero (see also Schmalz, Altoè, \& Mulatti, 2017 on other methodological problems). These meta-analyses show that age is a further significant factor: the SL impairment is more prominent in children than in adults in both the visuomotor and visual domains. 
Importantly, acoustic statistical learning has received much less attention in dyslexia than the visual domain. Dobó and colleagues (2021) found less efficient AGL in DD with verbal acoustic stimuli. Kahta and Schiff (2019) tested AGL in the acoustic modality with musical tones in adults with DD, and observed deficient learning. Statistical segmentation abilities also show deficits in different domains and modalities in DD. Relying on the word segmentation paradigm (Saffran, Newport, \& Aslin, 1996), Gabay and colleagues (2015) found deficient learning in high-functioning university students with DD relative to age and IQ matched controls with both linguistic and non-linguistic stimuli in the acoustic domain with very brief $(<3$-minute) training and an explicit $2 \mathrm{AFC}$ test, although both groups displayed significantly above chance learning levels. They also observed significant correlations between learning indices in the two domains (verbal and visual) and several measures of reading ability.

To sum up, statistical learning plays an important role in spoken and written language acquisition and use. Impairments of this learning mechanism seem to be present in the case of reading difficulties, for instance, in the case of developmental dyslexia. However, the small number of findings so far have not supported the statistical learning vulnerability in developmental dyslexia unequivocally.

\subsection{Motivation and aims}

Our aims in this study were 1) to test the efficiency of statistical learning in three groups with different levels of reading fluency, 2) with a potentially more valid online segmentation task and to compare the sensitivity of online versus offline measures in both typical and atypical readers, 3) to compare the efficiency of statistical learning in the acoustic versus visual domains in DD, and 4) to test the association of verbal and visual SL with reading skills. 
1. SL can be tested in many different areas and with many different tasks. In this study, we employed segmentation tasks. Segmentation abilities are important in reading development in both the acoustic and visual domains. In the acoustic domain, deficits in phonological awareness involving the ability to segment linguistic stimuli into smaller components (most often words into syllables and phonemes) are frequently associated with reading difficulties (Bruck, 1992; Kahta \& Schiff, 2019; Qi, Araujo, Georgan, Gabrieli \& Arciuli, 2019; Ramus et al., 2003; Snowling, 1998; Swan \& Goswami, 1997). Segmentation in the visual modality is less obviously relevant, as word boundaries in reading are clearly marked by spaces. Skilled readers rely on recognizing frequent and reliable sublexical chunks of graphemes (Siegelman et al., 2020). Visual segmentation and fast recognition of prefixes also benefit the reading of morphologically complex words, especially in morphologically rich languages like Hungarian. These factors make testing segmentation abilities both in the acoustic and visual domains well motivated.

2. Beyond controversial findings based on diverse methods, our study was motivated by methodological concerns about the efficiency of explicit offline measures of SL from judgment tasks (see e.g. Isbilen, McCauley, Kidd, \& Christiansen, 2017; Siegelman, Bogaerts, \& Frost, 2017). In most experimental designs, after the training phase participants are required to explicitly reflect upon the grammatical well-formedness of artificial strings in some form. Such tests yield explicit measures building on metalinguistic awareness, which can distort results and may not truly reflect the effectiveness of the learning process in SL, especially in neurodevelopmental disorders, where memory and metacognitive abilities required for the judgment task may themselves be impaired. In online versions of SL tasks, participants become more active in learning, e.g. by having to press a key when they hear a syllable (syllable monitoring). During the training phase, target patterns become implicitly more and more 
predictable resulting in quicker button presses. The time between the appearance of the stimulus and the response is informative of the learning process: as participants learn the pattern, reaction times shorten.

3. Based on the empirical findings related to dyslexia, deficits in SL can occur in both the visual and the acoustic domain. As SL is a multimodal neurocognitive system suggested to operate on modality-specific representations with modality-specific constraints (Frost et al., 2015), both problems with processing modality-specific stimuli and an impairment of the learning mechanism can result in SL deficits. Prominent impairments in phonological representations and processing in DD together with less obvious or no impairments in nonlinguistic visual processing suggest that the gravity of SL problems may differ across modalities and domains, and invite further research with direct comparisons of performance across similar tasks from the same group of participants both with and without DD.

4. Because both reading skill and cognitive abilities vary greatly not just in developmental disorders but also in the typical populations (see above), we decided to compare performance across three instead of two groups, based on reading fluency: in groups of readers with High Reading Fluency (HRF), Medium Reading Fluency (MRF), Low Reading Fluency (LRF).

Motivated by the necessity of measures that are more sensitive to learning and individual/group differences, and to gain a more accurate picture of the statistical learning in different domains in dyslexia, we aimed to test both visual and acoustic SL with the same task design, relying on both online and offline measures. We explored segmentation abilities in the acoustic verbal and visual nonverbal domain in online target detection tasks, where the extent of learning is reflected in the differences between RTs to predictable versus unpredictable targets. Explicit judgments of well-formedness were also elicited in a 2AFC task. We also assessed 
verbal short-term and working memory to control for their effects on verbal SL. We formulated the following hypotheses:

1. SL performance will be associated with reading fluency, resulting in the following pattern across groups: $\mathrm{LRF}<\mathrm{MRF}<\mathrm{HRF}$.

2. This pattern will be present in both the acoustic and visual domains.

3. This pattern will be observed in both online and offline measures.

4. Since they are less confounded by other factors, online SL measures will be more sensitive to SL than $2 \mathrm{AFC}$ scores, therefore, we expect to see evidence of learning in online measures even when 2AFC shows no evidence of learning.

\section{Materials and methods}

\subsection{Participants}

Eighty-one Hungarian adolescents participated in the study. Three participants were excluded from the study due to IQ scores at or below 85 points, and further five participants were also excluded because of misunderstanding the instructions and failing to complete the Segmentation Tasks. They were all native speakers of Hungarian recruited from three secondary schools in Budapest. One of these institutions was a school in which students with learning difficulties were integrated, while the other two were mainstream secondary schools. We recruited participants with reading difficulties from the integrating school based on the expert opinion of a speech-therapist from the institution. Although many of these students had previous diagnoses of DD, we decided not to establish group membership based on these diagnoses, since no standardized diagnostic tools are available for adolescents in Hungary, and students had been examined with highly diverse methods. Since reading fluency is the most reliable indicator of reading disorders in both opaque (Breznitz \& Misra, 2003; Compton \& Carlisle, 1994; Wimmer 
\& Mayringer, 2002) and transparent languages (e.g., Re, Tressoldi, Cornoldi \& Lucangeli, 2011), we applied a reading fluency task to measure reading skills uniformly both in participants with a previous diagnosis of DD and in participants without a diagnosis and/or reading problems.

Based on reading fluency (One Minute Reading Test, OMRT), participants were classified into three groups. In the OMRT, participants were given a printed text on paper and were asked to read it aloud. The reading index was the number of syllables read in 60 seconds. Raw syllable counts were normalized based on data from a larger sample of adolescents (Lukács, Kas, Takács, \& Vidnyánszky, 2021). Participants scoring at or below -1.5 SDs were classified as readers with low reading fluency (LRF), those who had an OMRT score between -1.5 and -0.5 SDs were assigned to the group with medium reading fluency (MRF), and readers scoring above -0.5 SDs were assigned to the group with high reading fluency (HRF). The three groups were matched at the group level on group size, age and IQ score, resulting in the inclusion of 63 adolescents altogether (21 participants in each group). Most, but not all participants with a former diagnosis of DD belonged to the LRF group. In total, six participants had a DD diagnosis in the LRF group, three participants in the MRF group, and no participant in the HRF group. Demographic data, reading measures and other background measures investigating short term and working memory (forward and backward digit span, non-word repetition task; Hungarian versions: Racsmány, Lukács, Németh, \& Pléh, 2005) for the three groups are given in Table 1. All participants were tested with the informed consent of their parents together with their own informed consent, in accordance with the principles set out in the Declaration of Helsinki and the stipulations of the local Institutional Review Board.

Table 1

Demographic data and reading measures in the three groups 


\begin{tabular}{|c|c|c|c|c|c|}
\hline & LRF & MRF & HRF & $\chi^{2}(2)$ & $p$ \\
\hline Females/Males & $0 / 21$ & $3 / 18$ & $3 / 18$ & & \\
\hline Age in years & $17.5(1.4)$ & $17.7(1.3)$ & $17.6(1.3)$ & 0.47 & .790 \\
\hline Raven IQ & $109.6(9.4)$ & $110.4(11.4)$ & $110.5(10.3)$ & 0.26 & .880 \\
\hline OMRT z-score & $-2.2(0.5)$ & $-0.9(0.3)$ & $0.1(0.5)$ & 55.18 & $<.001$ \\
\hline Forward digit span & $5.62(1.10)$ & $5.95(0.97)$ & $6.10(1.33)$ & 1.37 & .504 \\
\hline Backward digit & $4.33(0.86)$ & $4.65(0.93)$ & $5.14(1.46)$ & 3.76 & .153 \\
\hline span & & & & & \\
\hline Non-word & $6.38(1.02)$ & $6.57(0.93)$ & $6.55(1.28)$ & 0.47 & .792 \\
\hline
\end{tabular}

$\overline{\text { Note. Proportions are displayed for ratios of males and females, means and standard deviations (in parentheses) are }}$ displayed for Age, Raven IQ, OMRT z-scores, Forward digit span, Backward digit span, and Non-word repetition task. As measures were not normally distributed, we tested the difference of groups with a Kruskal-Wallis test. LRF = low reading fluency, MRF = medium reading fluency, $\mathrm{HRF}=$ high reading fluency.

\subsection{Stimuli}

The segmentation tasks were modelled after Saffran and colleagues' $(1996,1999)$ seminal studies. Besides the traditional tests, the current version of the paradigm includes an online target detection task to detect the acquisition of statistical patterns during the learning phase (Lukics \& Lukács, 2021; see also Batterink \& Paller, 2017; Franco, Eberlen, Destrebecqz, Cleeremans, \& Bertels, 2015; and Siegelman et al., 2017; for similar designs). In addition to the acoustic verbal version of the task, we also administered a visual nonverbal version with the same design. 


\subsubsection{Verbal acoustic segmentation task}

Stimuli in the verbal acoustic segmentation task consisted of 12 recorded nonsense consonant-vowel syllables (cé/tse:/, de /de/, gá/ga:/, go /go/, ha /hp/, ki /ki/, mü/my/, pe /pe/, sá / $\mathrm{a}: /$, tu $/ \mathrm{tu} /$, ta $/ \mathrm{tb} /$, vi /vi/) spoken by a male Hungarian speaker. Syllables were recorded in isolation to prevent coarticulation effects, and were manipulated in Praat. As a result, all recordings had a pitch of $130 \mathrm{~Hz}$, a length of $400 \mathrm{~ms}$, and maximum intensities between 76.6 and $83.5 \mathrm{~dB}$. Sound intensities of syllables were judged to be equal by two independent listeners, resulting in monotonous stimuli which did not provide any prosodic cues to segmentation. For the online training phase, syllables were structured into five streams. In four of these streams, syllables were organized into four words (cégávi, detamü, hagoki, sápetu), and these words followed each other in a pseudorandom order with the constraint that the same word could not occur twice subsequently (word streams). In these word streams, TPs within words were 1, while TPs at word boundaries were 0.33 . In a fifth stream, individual syllables followed a pseudorandom order in a way that two syllables could not occur twice subsequently (random stream). In all of the streams, syllables were presented with pauses of $120 \mathrm{~ms}$ between them, resulting in a presentation rate of $520 \mathrm{~ms}^{2}$ The only cues for word boundaries were TPs. In each stream, 180 syllables were presented, each syllable with an equal frequency of occurring 15 times within each block, both in word and random streams.

For the $2 \mathrm{AFC}$ task, we used the four words from the training streams. In addition, we created four part-word (syllable triplets spanning a word boundary in the word streams), and four nonword (syllable triplets not occurring together in the word streams) foils. Stimuli for the verbal acoustic task are provided in Table 2 .

\footnotetext{
${ }^{2}$ The duration of pauses, thus the presentation rate, was a feature of the E-Prime software which we could not modify.
} 
Table 2

Words, part-words and non-words used in the 2AFC task

\begin{tabular}{ccc}
\hline Words & Part-words & Non-words \\
\hline cégávi & kicégá & céhatu \\
\hline detamü & mühago & gápego \\
\hline hagoki & tudeta & mütavi \\
\hline sápetu & visápe & \\
\hline
\end{tabular}

\subsubsection{Nonverbal visual segmentation task}

Stimuli for the nonverbal visual task consisted of 12 monochrome (black and white) symbols that were difficult to verbalize. The vertical size of stimuli was $3 \mathrm{~cm}$, and participants viewed them from a distance of approximately $60 \mathrm{~cm}$ from the screen. The 12 symbols were organized into four words, and these words followed each other in a pseudorandom order with the constraint that a given word could not occur twice in a row (word streams). Altogether, participants were presented with four word streams, where TPs within words were 1, while TPs on word boundaries were 0.33 . In a fifth stream, individual symbols followed each other in a pseudorandom order with the constraint that a given symbol could not occur twice in a row (random stream). In each stream, 180 symbols were presented, each symbol with an equal frequency of occurring 15 times within each block, both in word streams and in the random stream. Symbols were presented at a presentation rate of $420 \mathrm{~ms}^{3}$

For the $2 \mathrm{AFC}$ task, we used the four words from the training, and we created four part-word (symbol triplets spanning a word boundary in the word streams), and four non-word (symbol

\footnotetext{
${ }^{3}$ The duration of pauses between symbols $(20 \mathrm{~ms}$ ) was a feature of the E-Prime software which we could not modify, so we added it to the presentation rate.
} 
triplets not occurring together in the word streams) foils. Stimuli for the nonverbal visual task are provided in Figure 1.

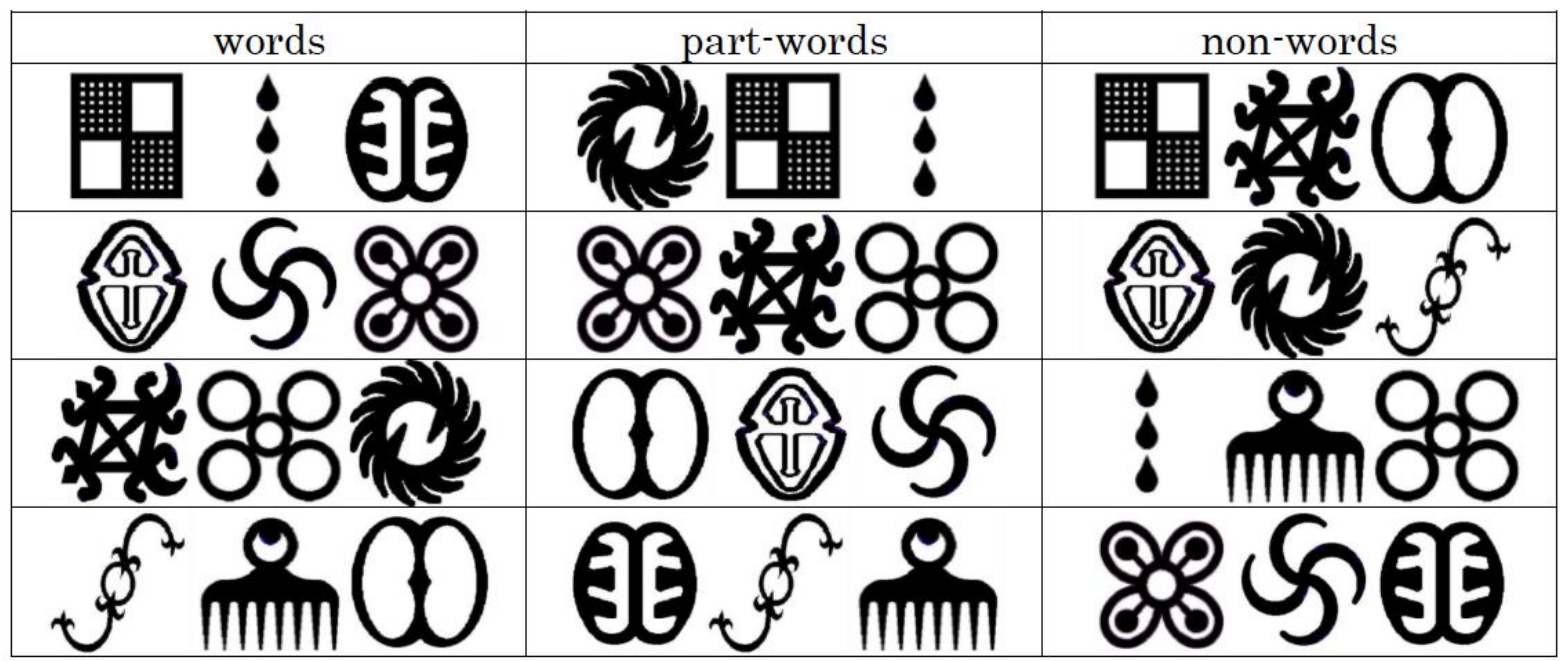

Figure 1. Stimuli in the nonverbal visual task

\subsection{Task and procedure}

Tasks were administered in silent classrooms of the schools in small groups. Acoustic stimuli were presented over headphones and the tests were recorded using the E-Prime 2.0 Professional software (Psychology Software Tools Inc., Pittsburgh, PA, USA).

Participants listened to stimuli through headphones in the verbal acoustic task, and viewed stimuli on the computer screen in the nonverbal visual task. The first phase of both tasks was an online learning phase based on the design of the Serial Reaction Time Task (Nissen \& Bullemer, 1987), aimed at tapping into the online process of learning. During listening to the speech stream or watching the symbol stream, participants' task was to respond to a target syllable or symbol (the same item throughout the entire online session). This target was the last item of one of the four three-item words, counterbalanced across participants. Last items were chosen as targets because previous work has shown that in target detection tasks participants show the most reliable learning effect in RT decreases to the last syllables of words in speech segmentation 
tasks (as opposed to middle-position syllables; Batterink, Reber, Neville, \& Paller, 2015; Franco et al., 2015). The online training phase consisted of three streams in three training blocks (Blocks TRN1 to TRN3). Each training stream consisted of 60 words, so altogether, 180 words were presented during training; each of the four words were presented 45 times. In the training blocks we measured how efficiently participants predict the target syllable or symbol through the course of learning, reflected in the changes in reaction times and accuracies over time. We also included two test blocks in the online tasks. The first test block was the random stream, where the word structure was disrupted, and syllables or symbols followed each other in a pseudorandom order (Block RND4). Block RND4 was the baseline or reference block, as the target item was not predictable, so RTs and accuracies were only influenced by the general practice effect in the task. The second test block was a word stream again, serving as a recovery block (Block REC5). Throughout the five blocks, participants performed an item-detection task: they were instructed to respond by pressing the spacebar every time they heard or saw the target (specified in the instruction) as quickly and accurately as they could, and to press the key ' $\mathrm{A}$ ' in the case of any other syllable or symbol.

After the online task, offline learning measures were collected from a 2AFC task. In both acoustic verbal and visual nonverbal tasks, participants were presented with 24 pairs of threeitem sequences. We tested three types of contrasts here: word vs. part-word, word vs. non-word, and part-word vs. non-word sequences. Comparing different contrast types allows testing SL with different levels of sensitivity: the word vs. part-word contrast shows how sensitive participants are to differences between stronger compared to weaker TP distributions in triplets $(\mathrm{TP} 1=1 ; \mathrm{TP} 2=1$ vs. $\mathrm{TP} 1=0.33 ; \mathrm{TP} 2=1)$, the word vs. non-word contrast shows how sensitive participants are to differences between strong TP sequences over sequences with zero TPs (TP1 
$=1 ; \mathrm{TP} 2=1$ vs. TP1 $=0 ; \mathrm{TP} 2=0$ ), and finally, the part-word vs. non-word contrast is informative about whether participants favour even weaker TP sequences over sequences with zero TPs $(\mathrm{TP} 1=0.33 ; \mathrm{TP} 2=1$ vs. TP1 $=0 ; \mathrm{TP} 2=0)$. Sequences in each contrast were randomly selected for each participant, and the order of trigram types varied within contrasts. In each trial, participants heard or saw the two sequences, and they were instructed to indicate which one was more familiar based on the training streams. We quantified learning in accuracy rates: the number of correct answers divided by the number of all trials, yielding a number between 0 and 1.

\section{Results}

\subsection{Segmentation Tasks}

In the online target detection tasks, RTs were collected for accurate button presses for targets within a -600 to $1200 \mathrm{~ms}$ time window from stimulus onset. For each participant, we filtered responses with RTs outside the 1.5 interquartile range beyond the first and third quartiles of their RTs. To analyse reaction times, we calculated the median of RTs for each block by participant. We also report block accuracies. We further calculated three online indices for each participant. $R$ T training was calculated by subtracting median RTs in Block TRN3 from RTs in Block TRN1. RT difference was calculated by averaging the differences between median RTs in Block RND4 and Block TRN3, and Block RND4 and Block REC5. Unlike RT training, RT difference is not biased by motor practice effects, as these effects are present in the random reference block, as well as the neighbouring word blocks.

While $R T$ training and $R T$ difference show online learning performance, they do not reflect the dynamics of learning during the training blocks, as they do not separate participants with faster and slower RT decreases as long as they show the same overall decrease. To capture 
differences in the dynamics of learning, we created a third online learning measure, learning efficiency (Lukics \& Lukács, 2021). This was calculated by multiplying a learning speed score, a RND4-TRN3 RT difference score and a TRN3 RT spread score together:

learning efficiency $=$ learning speed $*$ RND4-TRN3 RT difference $*$ TRN3 RT spread

Learning speed shows how quickly RTs reached the level of the last training block (Block TRN3) within the training blocks (Blocks TRN1 to TRN3) on a trial-by-trial level in a given participant. The RND-TRN3 RT difference score indicates the difference between median reaction times in Block RND4 and Block TRN3. The TRN3 RT spread score describes the interquartile range of reaction times in Block TRN3. The latter two scores were included because learning speed in itself cannot reliably indicate that learning really occurred during the training blocks. For example, a participant may show quick learning (the same RTs at the beginning and at the end of the training) if their RTs did not decrease through the training blocks. But if their RTs at the end of the training were not different from RTs in the random block (Block RND4), or their RTs were too scattered at the end of training, the lack of change through Blocks TRN1 to TRN3 cannot be due to fast learning. For a more detailed description of the scores see Lukics \& Lukács (2021).

\subsubsection{Verbal acoustic segmentation}

Distributions of RTs and accuracies by group and block in the verbal acoustic task are shown in Figure 2 and Figure 3, respectively. 


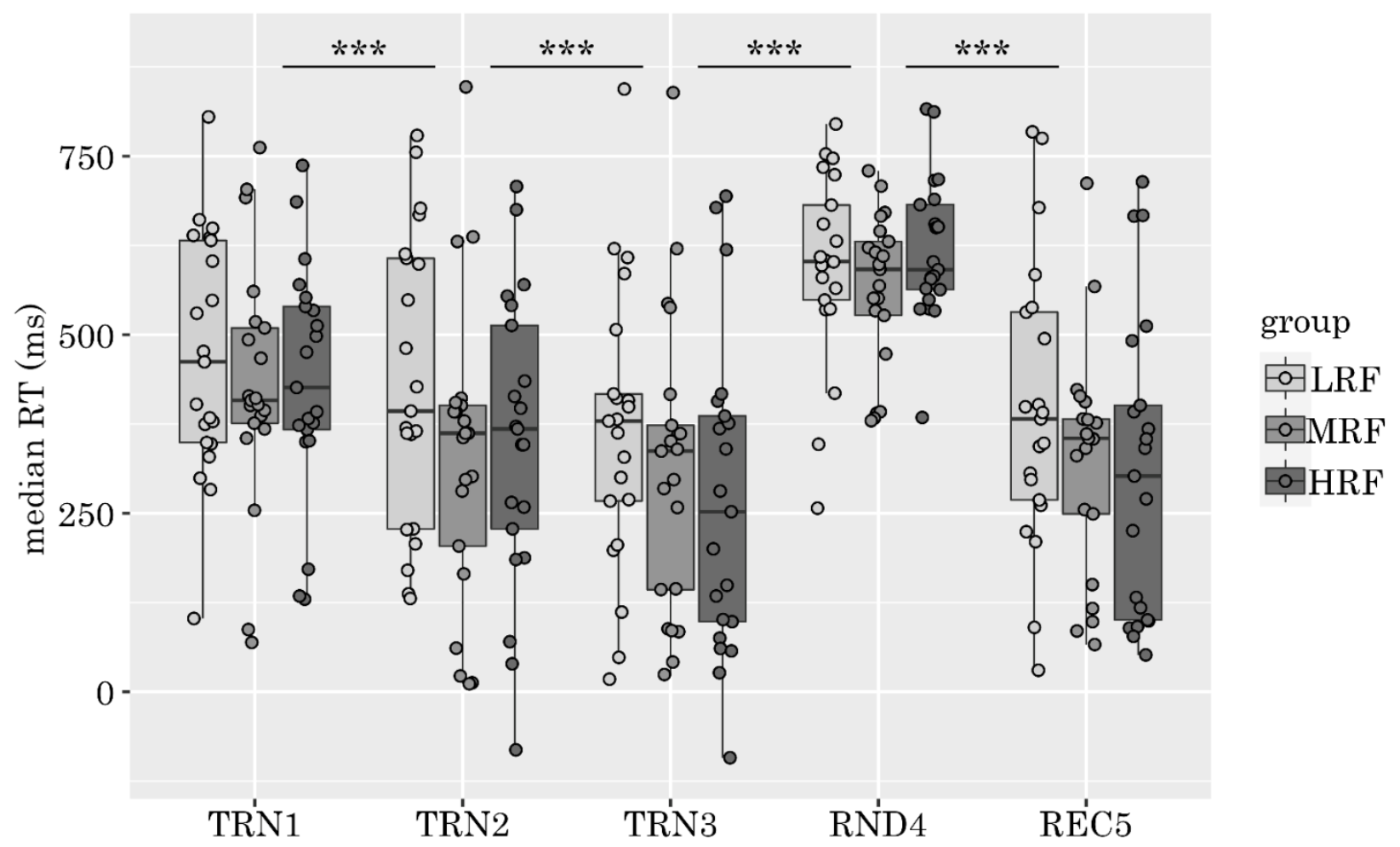

Figure 2. Change of RTs through blocks in the verbal acoustic condition. Dots represent the median RTs of individual participants in a given block (a small amount of jitter was added to increase visibility). Lines in boxes represent group medians, box lengths illustrate the group interquartile range, and whiskers show minimum and maximum values. Outliers are participant data which are outside the 1.5 interquartile range beyond the first and third quartiles. 


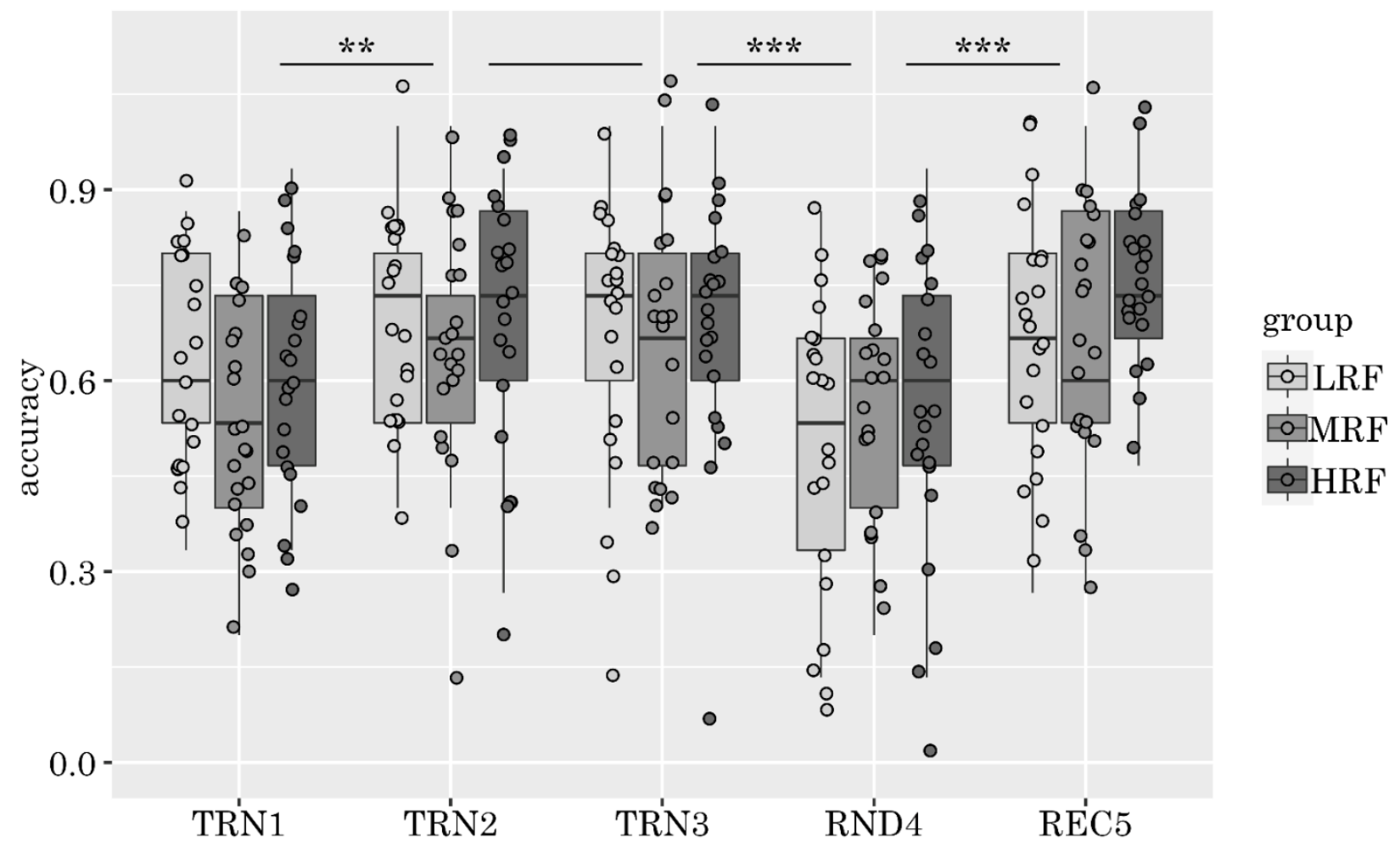

Figure 3. Accuracy rates across blocks in the verbal acoustic condition. Dots represent the accuracy rate of individual participants in a given block (a small amount of jitter was added to increase visibility). Lines in boxes represent group medians, box lengths illustrate the group interquartile range, and whiskers show minimum and maximum values. Outliers are participant data which are outside the 1.5 interquartile range beyond the first and third quartiles.

To investigate the effect of reading fluency on online learning in the acoustic verbal segmentation task, we performed a repeated measures ANOVA with a Greenhouse-Geisser correction on RT values with Block as a within-subject and Group as a between-subject factor. The main effect of Block was significant, $F(2.69,161.12)=61.93, p<.001, \eta_{p}{ }^{2}=.51$. Repeated contrast analyses showed that all neighbouring blocks significantly differed from each other $\left(\right.$ Block TRN1 > Block TRN2: $F(1,60)=21.29, p<.001, \eta_{p}{ }^{2}=.26,95 \%$ CI $[+42,+106]$; Block TRN2 > Block TRN3: $F(1,60)=13.34, p<.001, \eta_{p}{ }^{2}=.18,95 \%$ CI $[+26,+89]$; Block TRN3 < Block RND4: $F(1,60)=115.30, p<.001, \eta_{p}{ }^{2}=.66,95 \%$ CI $[-331,-226]$; Block RND4 > Block REC5: $F(1,60)=106.22, p<.001, \eta_{p}^{2}=.64,95 \%$ CI $\left.[+201,+299]\right)$. The main effect of Group 
was not significant, $F(2,60)=1.06, p=.354, \eta_{p}{ }^{2}=.03$. The interaction of Block and Group was not significant either, $F(5.37,161.12)=1.30 p=.265, \eta_{p}{ }^{2}=.04$.

We also investigated the change in accuracies through blocks and group effects on accuracy changes: we performed a repeated measures ANOVA with Block as a within-subject and Group as a between-subject factor. The main effect of Block was significant, $F(4,240)=$ $12.61, p<.001, \eta_{p}{ }^{2}=.17$. Repeated contrast analyses showed that there was a significant difference between the first two blocks (Block TRN1 < Block TRN2: $F(1,60)=9.72, p=.003$, $\eta_{p}{ }^{2}=.14,95 \%$ CI $\left.[-0.14,-0.03]\right)$. The difference between the second and third training blocks was not significant (Block TRN2 < Block TRN3: $F(1,60)=0.21, p=.648, \eta_{p}^{2}<.01,95 \%$ CI [$0.06,+0.04])$. However, accuracies in the random block were significantly lower than in the neighbouring blocks (Block TRN3 > Block RND4: $F(1,60)=19.46, p<.001, \eta_{p}{ }^{2}=.25,95 \%$ CI $[+0.08,+0.22]$; Block RND4 < Block REC5: $F(1,60)=29.25, p<.001, \eta_{p}{ }^{2}=.33,95 \%$ CI $[-0.23$, -0.11]). The main effect of Group was not significant, $F(2,60)=0.72, p=.491, \eta_{p}{ }^{2}=.02$. The interaction of Block and Group was not significant either, $F(8,240)=0.91, p=.506, \eta_{p}^{2}=.03$. 
Table 3

Descriptive and comparative statistics of $R T$ training, $R T$ difference and $2 A F C$ by group in the verbal acoustic segmentation task

\begin{tabular}{|c|c|c|c|c|c|c|c|c|c|c|c|c|c|c|}
\hline Group & & $\mathrm{LRF}$ & & & & MRF & & & & $\mathrm{HRF}$ & & & & \\
\hline Measure & $\begin{array}{l}\text { Mean } \\
(S D)\end{array}$ & $95 \% \mathrm{CI}$ & $t$ or $Z$ value & $r$ & $\begin{array}{l}\text { Mean } \\
(S D)\end{array}$ & $95 \% \mathrm{CI}$ & $t$ or $Z$ value & $r$ & $\begin{array}{l}\text { Mean } \\
(S D)\end{array}$ & $95 \% \mathrm{CI}$ & $t$ or $Z$ value & $r$ & $\begin{array}{l}F \text { or } \chi^{2} \\
\text { value }\end{array}$ & $\eta_{p}^{2}$ \\
\hline \multirow[t]{2}{*}{$\mathrm{RT}$ training $(\mathrm{ms})$} & & & $t(20)=$ & & 119 & & $t(20)=$ & & 168 & & $t(20)=$ & & $F(2,63)=$ & \\
\hline & $106(154)$ & {$[+36,+176]$} & $3.15^{* *}$ & .58 & $(184)$ & {$[+35,+203]$} & $2.96 * *$ & .55 & $(154)$ & {$[+98,+238]$} & $5.02 * * *$ & .75 & 0.84 & .03 \\
\hline \multirow[t]{2}{*}{ RT difference (ms) } & & {$[+130$} & $t(20)=$ & & 247 & {$[+176$} & $t(20)=$ & & 331 & {$[+227$} & $t(20)=$ & & $F(2,63)=$ & \\
\hline & $215(187)$ & $+300]$ & $5.27 * * *$ & .76 & $(155)$ & $+317]$ & $7.28 * * *$ & .85 & $(228)$ & $+434]$ & $6.65^{* * *}$ & .83 & 2.02 & .06 \\
\hline Learning & 0.05 & {$[+0.02$} & & & 0.06 & {$[+0.02$} & & & 0.09 & {$[+0.04$} & & & & \\
\hline efficiency & $(0.07)$ & $+0.08]$ & $Z=3.20 * * *$ & .70 & $(0.09)$ & $+0.10]$ & $Z=3.33^{* * *}$ & .73 & $(0.11)$ & $+0.14]$ & $Z=3.85^{* * *}$ & .84 & $\chi^{2}(2)=2.88$ & .05 \\
\hline 2AFC accuracy: & 0.61 & {$[+0.55$} & $t(20)=$ & & 0.66 & {$[+0.60$} & $t(20)=$ & & 0.70 & {$[+0.65$} & $t(20)=$ & & $F(2,63)=$ & \\
\hline overall & $(0.12)$ & $+0.66]$ & $4.02 * * *$ & .67 & $(0.12)$ & $+0.71]$ & $6.18 * * *$ & .81 & $(0.13)$ & $+0.76]$ & $7.22 * * *$ & .85 & $3.47^{*}$ & .10 \\
\hline 2AFC accuracy: & 0.63 & {$[+0.58$} & $t(20)=$ & & 0.68 & {$[+0.60$} & $t(20)=$ & & 0.68 & {$[+0.60$} & $t(20)=$ & & $F(2,63)=$ & \\
\hline word > part-word & $(0.12)$ & $+0.69]$ & $4.93^{* * *}$ & .74 & $(0.18)$ & $+0.76]$ & $4.46^{* * * *}$ & .71 & $(0.20)$ & $+0.77]$ & $4.40 * * *$ & .70 & 0.64 & .02 \\
\hline
\end{tabular}




\begin{tabular}{|c|c|c|c|c|c|c|c|c|c|c|c|c|c|c|}
\hline 2AFC accuracy: & 0.69 & {$[+0.58$} & $t(20)=$ & & 0.73 & {$[+0.65$} & $t(20)=$ & & 0.76 & {$[+0.69$} & $t(20)=$ & & $F(2,63)=$ & \\
\hline word $>$ non-word & $(0.24)$ & $+0.80]$ & $3.70 * *$ & .64 & $(0.18)$ & $+0.81]$ & $5.92 * * *$ & .80 & $(0.15)$ & $+0.83]$ & $7.86 * * *$ & .87 & 0.73 & .02 \\
\hline \multicolumn{15}{|l|}{ 2AFC accuracy: } \\
\hline part-word > non- & 0.49 & {$[+0.41$} & & & 0.57 & {$[+0.49$} & & & 0.66 & {$[+0.58$} & $t(20)=$ & & $F(2,63)=$ & \\
\hline word & $(0.18)$ & $+0.58]$ & $t(20)=-0.15$ & .03 & $(0.17)$ & $+0.64]$ & $t(20)=1.81$ & .37 & $(0.20)$ & $+0.75]$ & $4.00 * * *$ & .67 & $4.94 *$ & .14 \\
\hline
\end{tabular}

Note. Learning effects for each measure are indicated with asterisks. Significance of learning effect: $*: p<.05, * *: p<.01, * * * p<.001$. A value of 0 indicates no learning for $R T$ training and $R T$ difference and a value of 0.5 indicates no learning in the case of $2 A F C$ accuracy. Tests for group differences are also displayed for each measure. As learning efficiency measures did not have a normal distribution, nonparametric tests were used to test this measure. 
Descriptive statistics for $R T$ training and $R T$ difference from the online task, and $2 A F C$ from the offline tasks in the verbal acoustic task, as well as group differences in these indices are shown in Table 3. When examining online RT indices in the three groups, we observed significant learning on all indices ( $R T$ training, $R T$ difference, learning efficiency). $2 A F C$ accuracy was also significantly different from chance level in all groups. In the 2AFC task, the word > part-word and word > non-word contrasts were different from chance level in all groups, while in the case of the part-word > non-word contrast, only the HRF group's performance differed from chance level. When investigating Group differences, we found that Group had a significant effect only on the offline 2AFC accuracy: overall and 2AFC accuracy: part-word > non-word measures. In the case of 2AFC: overall, post hoc Tukey HSD comparisons revealed that only the LRF and HRF groups differed from each other significantly, $p=.029,95 \%$ CI [$0.19,-0.01]$, there was no significant difference either between LRF and MRF groups, $p=.364$, 95\% [-0.14, +0.04]; or MRF and HRF groups, $p=.423,95 \%[-0.14,+0.04]$. Group also had a significant effect on 2AFC accuracy: part-word > non-word. Post hoc Tukey HSD comparisons revealed that only the LRF and HRF group differed from each other significantly, $p=.008,95 \%$ $[-0.31,-0.04]$. There was no significant difference either between the LRF and MRF groups, $p=$ $.406,95 \%[-0.06,+0.20]$, or between the MRF and HRF groups, $p=.168,95 \%[-0.03,+0.23]$.

\subsubsection{Nonverbal visual segmentation}

Distributions of RTs and accuracies by group and block in the nonverbal visual task are shown in Figure 4 and Figure 5, respectively. 


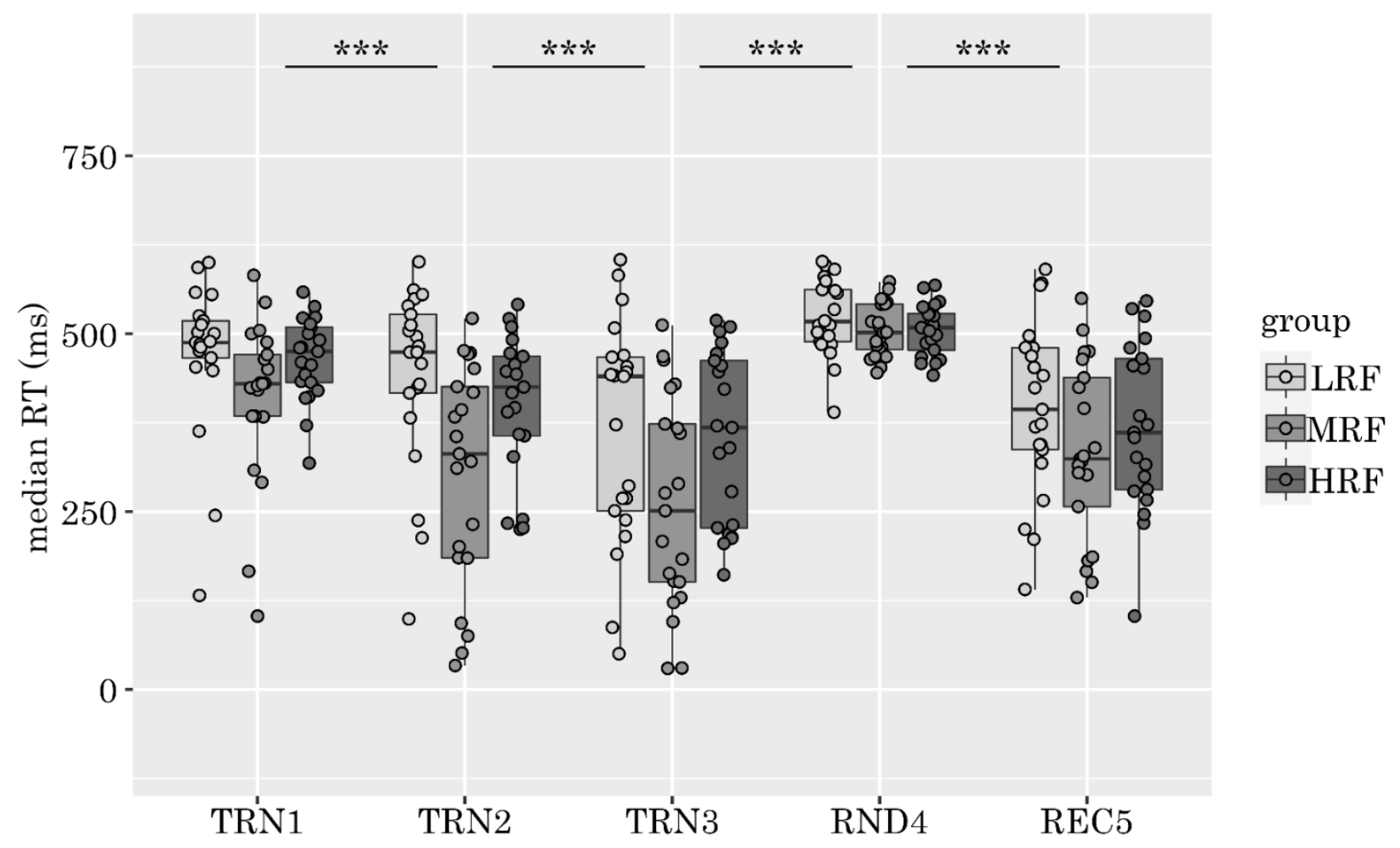

Figure 4. Median RTs across blocks in the nonverbal visual condition. Dots represent the median RTs of individual participants in a given block (a small amount of jitter was added to increase visibility). Lines in boxes represent group medians, box lengths illustrate the group interquartile range, and whiskers show minimum and maximum values. Outliers are participant data which are outside the 1.5 interquartile range beyond the first and third quartiles. 


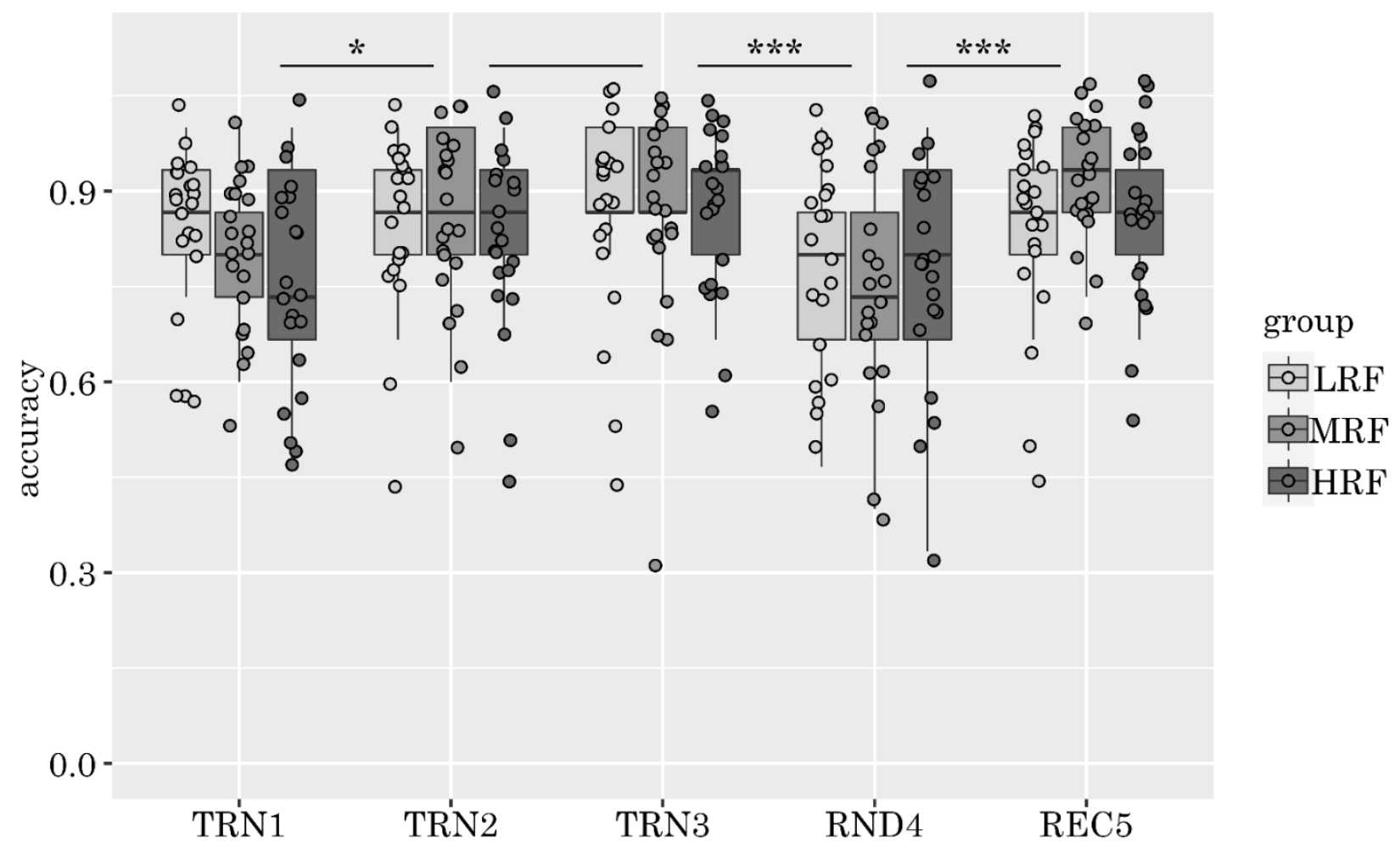

Figure 5. Accuracy rates across blocks in the nonverbal visual condition. Dots represent the accuracy rate of individual participants in a given block (a small amount of jitter was added to increase visibility). Lines in boxes represent group medians, box lengths illustrate the group interquartile range, and whiskers show minimum and maximum values. Outliers are participant data which are outside the 1.5 interquartile range beyond the first and third quartiles.

To investigate the effect of reading fluency on online learning in the visual segmentation task, we performed a repeated measures ANOVA with a Greenhouse-Geisser correction on RTs with Block as a within-subject and Group as a between-subject factor. The main effect of Block was significant, $F(2.81,168.53)=49.30, p<.001, \eta_{p}{ }^{2}=.45$. Repeated contrast analyses showed that all neighbouring blocks significantly differed from each other (Block TRN1 > Block TRN2: $F(1,60)=29.43, p<.001, \eta_{p}^{2}=.33,95 \%$ CI $[+41,+91] ;$ Block TRN2 $>$ Block TRN3: $F(1,60)=$ 23.14, $p<.001, \eta_{p}{ }^{2}=.28,95 \%$ CI $[+33,+79]$; Block TRN3 < Block RND4: $F(1,60)=98.50, p<$ $.001, \eta_{p}{ }^{2}=.62,95 \%$ CI $[-223,-147]$; Block RND4 > Block REC5: $F(1,60)=93.13, p<.001, \eta_{p}{ }^{2}$ 
$=.61,95 \% \mathrm{CI}[+115,+174])$. The main effect of Group was also significant, $F(2,60)=4.52, p=$ $.015, \eta_{p}{ }^{2}=.13$. Post hoc Tukey HSD tests showed that only LRF and MRF groups differed, $p=$ $.014,95 \% \mathrm{CI}[+13,+139]$; there was no significant difference either between the MRF and HRF groups, $p=.089,95 \%$ CI $[-120,+7]$; or the LRF and HRF groups, $p=0.735,95 \%$ CI $[-43,+83]$. The interaction of Block and Group was not significant, $F(5.62,168.53)=1.97, p=.078, \eta_{p}{ }^{2}$ $=.06$.

We also investigated the change in accuracies through blocks and group effects on accuracy changes: we performed a repeated measures ANOVA with Block as a within-subject and Group as a between-subject factor. The main effect of Block was significant, $F(4,240)=$ $8.99, p<.001, \eta_{p}^{2}=.13$. Repeated contrast analyses revealed that there was a significant difference between the first two blocks (Block TRN1 < Block TRN2: $F(1,60)=5.05, p=.028$, $\eta_{p}{ }^{2}=.08,95 \%$ CI $\left.[-0.09,-0.01]\right)$. The difference between the second and third training blocks was not significant (Block TRN2 < Block TRN3: $F(1,60)=1.73, p=.194, \eta_{p}{ }^{2}=.03,95 \%$ CI [$0.07,+0.01])$. However, accuracies in the random block were significantly lower than in the neighbouring blocks (Block TRN3 > Block RND4: $F(1,60)=15.77, p<.001, \eta_{p}{ }^{2}=.21,95 \% \mathrm{CI}$ $[+0.05,+0.16] ;$ Block RND4 < Block REC5: $F(1,60)=19.19, p<.001, \eta_{p}^{2}=.24,95 \%$ CI $[-0.15$, $-0.06])$. The main effect of Group was not significant, $F(2,60)=0.52, p=.600, \eta_{p}^{2}=.02$. The interaction of Block and Group was not significant either, $F(8,240)=1.02, p=.423, \eta_{p}{ }^{2}=.03$. 
Table 4

Descriptive and comparative statistics of $R T$ training, $R T$ difference and $2 A F C$ by group in the nonverbal visual online target detection task

\begin{tabular}{|c|c|c|c|c|c|c|c|c|c|c|c|c|c|c|}
\hline Group & & LRF & & & & MRF & & & & $\mathrm{HRF}$ & & & & \\
\hline Measure & $\begin{array}{l}\text { Mean } \\
(S D)\end{array}$ & $95 \% \mathrm{CI}$ & $t$ or $Z$ value & $r$ & $\begin{array}{l}\text { Mean } \\
(S D)\end{array}$ & $95 \% \mathrm{CI}$ & $t$ or $Z$ value & $r$ & $\begin{array}{l}\text { Mean } \\
(S D)\end{array}$ & $95 \% \mathrm{CI}$ & $t$ or $Z$ value & $r$ & $F$ or $\chi^{2}$ value & $\eta_{p}^{2}$ \\
\hline \multirow[t]{2}{*}{ RT training (ms) } & & & & & & & $t(20)=$ & & 110 & & & & & \\
\hline & 107 (133) & {$[+47,+167]$} & $Z=3.46^{* *}$ & .76 & $148(151)$ & {$[+79,+217]$} & $4.49 * * *$ & .71 & $(105)$ & {$[+62,+158]$} & $Z=3.84 * * *$ & .84 & $\chi^{2}(2)=1.44$ & .02 \\
\hline \multirow[t]{2}{*}{ RT difference (ms) } & & & $t(20)=$ & & & {$[+152$} & $t(20)=$ & & 144 & & $t(20)=$ & & $F(2,63)=$ & \\
\hline & $144(134)$ & {$[+83,+205]$} & $4.93 * * *$ & .74 & 206 (119) & $+260]$ & $7.95^{* * *}$ & .87 & (119) & {$[+90,+198]$} & $5.54 * * *$ & .78 & 1.78 & .06 \\
\hline Learning & 0.04 & {$[+0.01$} & & & 0.06 & {$[+0.03$} & & & 0.04 & {$[+0.02$} & $t(20)=$ & & & \\
\hline efficiency & $(0.06)$ & $+0.07]$ & $Z=3.40^{* *}$ & .74 & $(0.07)$ & $+0.09]$ & $Z=4.02 * * *$ & .88 & $(0.04)$ & $+0.06]$ & $4.31^{* * *}$ & .69 & $\chi^{2}(2)=3.22$ & .05 \\
\hline \multirow[t]{2}{*}{ 2AFC accuracy } & 0.55 & {$[+0.50$} & $t(20)=$ & & 0.51 & {$[+0.45$} & & & 0.49 & {$[+0.44$} & & & $F(2,63)=$ & \\
\hline & $(0.12)$ & $+0.61]$ & $2.17 *$ & .44 & $(0.13)$ & $+0.56]$ & $t(20)=0.21$ & .05 & $(0.10)$ & $+0.54]$ & $t(20)=0.35$ & .08 & 1.70 & .05 \\
\hline 2AFC accuracy: & 0.51 & {$[+0.43$} & & & 0.43 & {$[+0.34$} & & & 0.46 & {$[+0.40$} & & & & \\
\hline word > part-word & $(0.19)$ & $+0.60]$ & $t(20)=0.29$ & .06 & $(0.20)$ & $+0.52]$ & $t(20)=1.67$ & .35 & $(0.15)$ & $+0.53]$ & $Z=1.05$ & .23 & $\chi^{2}(2)=1.77$ & .03 \\
\hline
\end{tabular}




\begin{tabular}{|c|c|c|c|c|c|c|c|c|c|c|c|c|c|c|}
\hline 2AFC accuracy: & 0.65 & {$[+0.56$} & $t(20)=$ & & 0.48 & {$[+0.39$} & & & 0.49 & {$[+0.42$} & & \multicolumn{3}{|c|}{$F(2,63)=$} \\
\hline word $>$ non-word & $(0.19)$ & $+0.74]$ & $3.55 * *$ & .62 & $(0.19)$ & $+0.56]$ & $t(20)=0.58$ & .13 & $(0.16)$ & $+0.56]$ & $t(20)=0.35$ & .08 & $6.03 * *$ & .17 \\
\hline \multicolumn{15}{|l|}{ 2AFC accuracy: } \\
\hline part-word > non- & 0.51 & {$[+0.44$} & & & 0.61 & {$[+0.51$} & & & 0.52 & {$[+0.42$} & & & & \\
\hline
\end{tabular}

Note. Learning effects for each measure are indicated with asterisks. Significance of learning effect: $*: p<.05, * *: p<.01, * * * p<.001$. A value of 0 indicated no learning for $R T$ training and $R T$ difference and a value of 0.5 indicated no learning in the case of $2 A F C$ accuracy. Tests for group differences are also displayed for each measure. As some measures did not have a normal distribution, nonparametric tests were used to test these measures. 
Descriptive statistics for $R T$ training and $R T$ difference from the online task, and $2 A F C$ from the offline tasks in the nonverbal visual task are shown in Table 4. When examining Group differences of online RT indices, we found significant learning in all of them (RT training, $R T$ difference, learning efficiency). 2AFC accuracy was significantly different from chance level in the LRF group, while the MRF and HRF groups performed at chance level. 2AFC accuracy: word > non-word only differed from chance level in the LRF group, while 2AFC accuracy: partword > non-word only differed from chance level in the MRF group. When investigating Group differences, we found that there was no difference between groups in the case of $R T$ training, $R T$ difference, or learning efficiency. Group had only a significant effect on 2AFC accuracy: word > non-word from the $2 \mathrm{AFC}$ measures. Post hoc Tukey HSD comparisons revealed that only the LRF and the MRF group, and the LRF and HRF group differed from each other significantly, $p=$ $.008,95 \% \mathrm{CI}[+0.04,+0.31], p=.014,95 \%$ CI $[+0.03,+0.29]$, respectively. There was no significant difference either between the MRF and HRF groups, $p=.975$, 95\% CI $[-0.15,+0.12]$.

\subsection{Relationship between reading fluency, working memory and statistical learning}

We tested correlations between reading fluency, measures of verbal STM and WM, and acoustic and visual SL measures in the entire sample. Reading fluency (measured by OMR) was not significantly associated with any measures of verbal STM or WM (forward digit span, backward digit span, non-word repetition span; all $p \mathrm{~s}>.050)$. We further tested the relationship between reading fluency and SL task measures (RT training, RT difference, learning efficiency, $2 A F C$ overall). In both the verbal acoustic and nonverbal visual tasks, none of the measures were significantly correlated with OMR task scores (all $p$ s $<.050$ ). We also analysed the correlation between STM and WM (forward digit span, backward digit span, non-word repetition span) and SL scores ( $R T$ training, $R T$ difference, learning efficiency, $2 A F C$ overall). In the verbal acoustic 
task, $R T$ training showed a significant correlation with backward digit span, $r_{s}=.30, p=.016$. No measures from the nonverbal visual task showed a significant correlation with STM or WM measures (all $p \mathrm{~s}>.050)$.

\section{Summary and Discussion}

The present study provides new results on SL abilities in individuals with different levels of reading fluency and examines the relationship between acoustic and visual SL and reading skills. We investigated segmentation abilities in three reading groups (LRF, MRF and HRF) in both the acoustic verbal and visual nonverbal modalities. Together with post-training 2AFC measures, we also employed an online target detection task (Lukics \& Lukács, 2021) to obtain measures of SL which are less confounded by metacognitive skills and are able to track SL in the course of learning. All participants were tested in both the visual and verbal modalities. This design allowed us 1) to compare SL in the groups of individuals with low, medium and high reading proficiency; 2) to compare the learning processes of different groups in different modalities; 3) to compare the efficiency of online and offline measures and 4) to test the relationship between SL and reading skills.

In the acoustic verbal segmentation task, RTs and accuracies showed significant learning effects in the online target detection task in all groups. The online indices of learning ( $R T$ training and $R T$ difference) did not show any group difference in the efficiency of learning: individuals with low and medium reading fluency were similar to participants with high reading fluency controls both in the training effect and in the sequence learning effect. No group differences were observed in the learning efficiency measure either, which aimed to differentiate between faster and slower learners in the target detection task. However, there were significant group differences in the offline 2AFC task: the HRF group scored significantly higher than the LRF group. The MRF 
group had nominally higher scores than the LRF and lower than the HRF group, but these differences were not statistically significant. A closer examination of different contrast types (word $>$ non-word, word > part-word and part-word > non-word) tested in the 2AFC task revealed that both word > non-word and word > part-word contrasts are robust indices of SL in the acoustic modality, while non-word > part-word contrasts may require greater sensitivity to TPs.

Better 2AFC performance in more skilled readers in the acoustic verbal task may reflect larger verbal STM and WM spans. However, in our study, this is contradicted by the observation that there was no statistically significant difference in STM and WM performance levels between the groups. While group differences in offline measures can reflect differences in other, unexamined cognitive skills, they can also result from differences in task design and sensitivity for the online and offline indices. The online task measured differences only between reactions to target syllables in words vs. target syllables in random sequences. In contrast, the $2 \mathrm{AFC}$ task tested discrimination in more diverse settings: words vs. part-words, words vs. non-words (random sequences) and part-words vs. non-words. More detailed analyses of these results show that groups only differed in their accuracy rates to the part-word > non-word contrast, which the online measures could not test. Individuals with LRF might be less sensitive to the discrimination of pairs with finer distinctions in overall transitional probabilities. It also has to be noted that 2AFC measures show lower reliability than online measures (e.g., Lukics \& Lukács, 2021), and there were nominal differences between groups in the case of the other contrast types as well. Different contrast types in the 2AFC task only consisted of eight trials each, resulting in potentially noisy data and a measure not reliable enough to serve as a basis of strong conclusions. However, this possibility needs further investigation (e.g., online tasks with different degrees of difficulty in transitional probability violations). 
As in the acoustic verbal task, online learning was also evident both in RTs and accuracies in the nonverbal visual segmentation task, reflected in the online learning indices of $R T$ training, $R T$ difference and learning efficiency. While there were group differences in overall RTs (between the LRF and MRF groups) there was no difference in online learning patterns across the three groups. Offline measures showed a different pattern in the visual than in the acoustic task: the MRF and the HRF groups performed at chance (the LRF group did not) and showed no evidence of learning in 2AFC scores. There were no group differences in 2AFC scores. In the visual modality, chance level performance was exceeded only by the LRF group, and closer examination of different contrast types revealed that even in that group, only the word > nonword contrast showed a learning effect. This implies that the sensitivity of the visual $2 \mathrm{AFC}$ task was lower than that of the verbal 2AFC task, and not sufficient to reflect learning in this modality. Overall, these results indicate that offline metacognitive measures can be especially taxing in the visual and/or nonverbal domain.

The patterns of online and offline results in the visual modality are in contrast with those observed by van Witteloostuijn and colleagues (2019), who found that the offline forced choice task was sensitive to visual SL, while their online RT measures failed to show significant learning effects in a group of 8-12-year old children with and without DD. These discrepant findings may be at least partially explained by methodological differences between the studies: 1) the visual stimuli might have been easier to verbalize in their task (aliens in different shapes and colours), 2) their forced choice task contained both $2 \mathrm{AFC}$ and $3 \mathrm{AFC}$ trials, while we used only 2 AFC trials, 3) their forced choice task consisted of 40 trials, while ours contained 24 trials -- both 2) and 3) make the offline part of the task more sensitive to individual and group 
differences, 4) they had a bigger sample of participants ( $\mathrm{n}=50$ in both groups), while in our experiment each group consisted of 21 participants.

We expected the pattern of SL abilities to parallel reading fluency in both the visual and acoustic domains, and in both online and offline measures. Our findings did not support our hypotheses concerning group differences: all groups were equally efficient in both acoustic and visual SL when learning was measured online. Reading fluency was only reflected in acoustic verbal offline $2 \mathrm{AFC}$ measures. We did not find significant correlations between reading fluency and any SL measures in the entire group either.

We found that online target detection tasks provide sensitive indices of learning: both RT and accuracy measures showed participants' increasing efficiency in predicting targets through the training blocks. Similarly, learning was evident in the differences between the random block and the neighbouring blocks both in RT and accuracy. Our hypothesis on the greater sensitivity of online than offline measures was strongly supported in both modalities: while all online indices proved to be efficient in tracking learning in both the acoustic verbal and the visual nonverbal SL tasks, offline measures only showed learning in the acoustic modality, where group differences were also observed.

Verbal acoustic and nonverbal visual segmentation showed analogous patterns in online measures, although raw RTs differed due to stimulus properties in the two tasks. Learning was observable in all groups through $2 \mathrm{AFC}$ scores only in the verbal condition. In the nonverbal task, only one group showed a significant learning effect. Even for the offline verbal measures, the evidence for SL impairment associated with reading difficulty is moderate, which suggests that the efficiency of SL is similar across groups in both modalities, and a lack of selective vulnerability in either domain. 
Taken together, these results show that reading problems are not associated with robust SL difficulties either in the verbal acoustic or in the visual domain, at least not in participants between 14 -- 18 years of age. These findings are in line with meta-analyses showing that the SL deficit is mostly present in younger children with reading difficulties (Lum, Ullman, \& ContiRamsden, 2013; van Witteloostuijn et al., 2017). This early SL delay may be compensated by adolescence: as children get older, they rely more on compensatory processes (such as pattern recognition or declarative memory) during performing SL tasks than children, which levels SL differences between the groups (van Witteloostuijn et al., 2017). The expected LRF $<$ MRF $<$ HRF pattern was only observed in the offline $2 \mathrm{AFC}$ measure of the acoustic verbal learning task, and the difference was only statistically significant between LRF and HRF groups. Had we not applied an online measure as well, $2 \mathrm{AFC}$ performance in itself would have suggested the existence of an SL deficit in the verbal acoustic domain in participants with reading difficulties, and a lack of SL in the visual nonverbal domain for all groups.

While there are several studies supporting the association between SL in nonverbal visual and visuomotor tasks and reading skills in both typical development and in dyslexia (Arciuli \& Simpson, 2012; Hedenius et al., 2013; Lum et al., 2013; Pavlidou \& Williams, 2014; Sigurdardottir et al., 2017; Steacy et al., 2019; Torkildsen, Arciuli, \& Wie, 2019; Vakil, Lowe, \& Goldfus, 2015; van den Bunt et al., 2018), there are also studies that do not find such a deficit (Henderson \& Warmington, 2017; Schmalz, Altoè, \& Mulatti, 2017; van den Bunt et al., 2018) and/or fail to observe an association between SL and reading skills. There are also results suggesting that the association between reading skills and acoustic SL may be stronger than the association with visual SL (Qi et al., 2018). Other results show that deficits in visual statistical learning may contribute not only to problems with reading, but problems with other visually 
complex objects like faces (Sigurdardottir et al., 2017). While it is clear from this varied picture that the presence and severity of the deficit is dependent on the domain, modality and nature of the SL task, on the reading task and on the age of participants, further studies are necessary to clarify how SL contributes to written and oral language skills, and whether SL deficits are causal in the reading difficulties, or accompany reading difficulties without contributing to them.

Our study is not without limitations. Participants were divided into three groups based on reading fluency, but we did not test reading comprehension. While relying on a more complex measure of reading abilities would have definitely given us a better picture of reading abilities, as there were no robust differences between groups in SL, it is unlikely to yield a different pattern on the relationship between reading and statistical segmentation abilities.

The choice and design of the SL task also raise potential methodological issues. One could argue that segmenting four three-syllable words might have been too easy for participants in this age group, even for participants with potential SL deficits. This is countered by evidence of online learning during the three training blocks both in RTs and in accuracy in both modalities, and far from ceiling (in the visual task, at chance) performance in the offline measures. Notwithstanding, further studies with both offline and online tasks better suited for testing variation within and across populations by including items differing in complexity could possibly yield a different pattern. In the current study, we focused on adolescents with different levels of reading fluency, but we believe this would be a line of research worth pursuing in younger participants with different reading skills.

Recently, Bogaerts and colleagues (2021) argued for specific hypotheses on the nature of the SL deficit and the language symptoms observed in this disorder. In line with this suggestion, we aimed to test segmentation abilities which are relevant in learning to read in both the acoustic 
and visual modality. We observed efficient learning in both modalities in all groups. Together with results and controversies from previous studies, these findings call for further and more targeted and specific hypotheses concerning the relationship of SL and reading.

\section{Conclusion}

We observed efficient learning in both acoustic and visual statistical segmentation tasks in all three groups with different levels of reading fluency. These findings argue against a robust SL impairment associated with reading difficulties in adolescents. Importantly, our results showed that offline and online measures can diverge in their sensitivity to learning on the same training material, and measuring learning online can provide more sensitive indices with a potential to offer a deeper understanding of statistical learning and of the deficit in dyslexia and other developmental disorders.

\section{Acknowledgments}

This work was supported by the Momentum Research Grant of the Hungarian Academy of Sciences (Momentum 96233 'Profiling learning mechanisms and learners: individual differences from impairments to excellence in statistical learning and in language acquisition', PI: Ágnes Lukács). During research and writing of the article, Ágnes Szőllősi was supported by the ÚNKP20-4-II-BME-13 New National Excellence Program of the Ministry for Innovation and Technology from the source of the National Research, Development and Innovation Fund, and Kornél Németh was supported by the National Research, Development and Innovation Office (PD18_128361) and ÚNKP-18-4 New National Excellence Program of the Ministry of Human Capacities and Janos Bolyai Research Scholarship of the Hungarian Academy of Sciences (ÚNKPBolyai+). We would like to express our gratitude to our participants and to the teachers, especially to Dóra Paveszka, Angelika Péntek and László Tóth, who provided invaluable help in organizing 
the testing sessions. We are also grateful to Fruzsina Józsa, Dóra Eszter Szabó, Adrienn Oláh, Anita Lencsés, Fanni Takátsy, Lilla Csernátonyi, Edina Török and Zsófia Miklós for their assistance in data collection.

\section{References}

American Psychiatric Association (APA). (2013). Diagnostic and Statistical Manual of Mental Disorders, Fifth Edition. American Psychiatric Association (APA).

Apfelbaum, K. S., Hazeltine, E., \& McMurray, B. (2013). Statistical learning in reading: Variability in irrelevant letters helps children learn phonics skills. Developmental Psychology, 49(7), 1348-1365. https://doi.org/10.1037/a0029839

Arciuli, J. (2018). Reading as Statistical Learning. Language Speech and Hearing Services in Schools, 49, 634. https://doi.org/10.1044/2018_LSHSS-STLT1-17-0135

Arciuli, J., \& Simpson, I. C. (2012). Statistical Learning Is Related to Reading Ability in Children and Adults. Cognitive Science, 36(2), 286-304. https://doi.org/10.1111/j.15516709.2011.01200.x

Batterink, L. J., \& Paller, K. A. (2017). Online neural monitoring of statistical learning. Cortex, 90, 31-45. https://doi.org/10.1016/j.cortex.2017.02.004

Batterink, L. J., Reber, P. J., Neville, H. J., \& Paller, K. A. (2015). Implicit and explicit contributions to statistical learning. Journal of Memory and Language, 83, 62-78. https://doi.org/10.1016/j.jml.2015.04.004

Boada, R., \& Pennington, B. F. (2006). Deficient implicit phonological representations in children with dyslexia. Journal of Experimental Child Psychology, 95(3), 153-193. https://doi.org/10.1016/j.jecp.2006.04.003

Bogaerts, L., Siegelman, N., \& Frost, R. (2021). Statistical Learning and Language Impairments: 
Toward More Precise Theoretical Accounts. Perspectives on Psychological Science, 16(2), 319-337. https://doi.org/10.1177/1745691620953082

Brady, S., Shankweiler, D., \& Mann, V. (1983). Speech perception and memory coding in relation to reading ability. Journal of Experimental Child Psychology, 35(2), 345-367. https://doi.org/10.1016/0022-0965(83)90087-5

Breznitz, Z., \& Misra, M. (2003). Speed of processing of the visual-orthographic and auditoryphonological systems in adult dyslexics: The contribution of "asynchrony" to word recognition deficits. Brain and Language, 85(3), 486-502. https://doi.org/10.1016/S0093-934X(03)00071-3

Bruck, M. (1992). Persistence of dyslexics' phonological awareness deficits. Developmental Psychology, 28(5), 874-886. https://doi.org/10.1037/0012-1649.28.5.874

Christiansen, M. H., Conway, C. M., \& Onnis, L. (2012). Similar neural correlates for language and sequential learning: Evidence from event-related brain potentials. Language and Cognitive Processes, 27(2), 231-256. https://doi.org/10.1080/01690965.2011.606666

Compton, D. L., \& Carlisle, J. F. (1994). Speed of word recognition as a distinguishing characteristic of reading disabilities. Educational Psychology Review, 6(2), 115-140. https://doi.org/10.1007/BF02208970

Conway, C. M., Karpicke, J., \& Pisoni, D. B. (2007). Contribution of Implicit Sequence Learning to Spoken Language Processing: Some Preliminary Findings With Hearing Adults. Journal of Deaf Studies and Deaf Education, 12(3), 317-334. https://doi.org/10.1093/deafed/enm019

Conway, C. M. (2020). How does the brain learn environmental structure? Ten core principles for understanding the neurocognitive mechanisms of statistical learning. Neuroscience \& 
Biobehavioral Reviews, 112, 279-299. https://doi.org/10.1016/j.neubiorev.2020.01.032

Conway, C. M., Bauernschmidt, A., Huang, S. S., \& Pisoni, D. B. (2010). Implicit statistical learning in language processing: Word predictability is the key. Cognition, 114(3), 356371. https://doi.org/10.1016/j.cognition.2009.10.009

Daltrozzo, J., Emerson, S. N., Deocampo, J., Singh, S., Freggens, M., Branum-Martin, L., \& Conway, C. M. (2017). Visual statistical learning is related to natural language ability in adults: An ERP study. Brain and Language, 166, 40-51. https://doi.org/10.1016/j.bandl.2016.12.005

Dobó, D., Lukics, K. S., Szőllősi, Á., Németh, K., \& Lukács, Á. (2021). Statistical Learning and the Effect of Starting Small in Developmental Dyslexia. Journal of Speech, Language, and Hearing Research, 1-15. https://doi.org/10.1044/2020_JSLHR-20-00145

Franco, A., Eberlen, J., Destrebecqz, A., Cleeremans, A., \& Bertels, J. (2015). Rapid Serial Auditory Presentation. Experimental Psychology, 62(5), 346-351. https://doi.org/10.1027/1618-3169/a000295

Freed, E. M., Hamilton, S. T., \& Long, D. L. (2017). Comprehension in proficient readers: The nature of individual variation. Journal of Memory and Language, 97, 135-153. https://doi.org/10.1016/j.jml.2017.07.008

Frost, R., Armstrong, B. C., Siegelman, N., \& Christiansen, M. H. (2015). Domain generality versus modality specificity: The paradox of statistical learning. Trends in Cognitive Sciences, 19(3), 117-125. https://doi.org/10.1016/j.tics.2014.12.010

Gabay, Y., Schiff, R., \& Vakil, E. (2012). Dissociation between the procedural learning of letter names and motor sequences in developmental dyslexia. Neuropsychologia, 50, 24352441. https://doi.org/10.1016/j.neuropsychologia.2012.06.014 
Gabay, Y., Thiessen, E. D., \& Holt, L. L. (2015). Impaired Statistical Learning in Developmental Dyslexia. Journal of Speech, Language, and Hearing Research: JSLHR, 58(3), 934-945. https://doi.org/10.1044/2015_JSLHR-L-14-0324

Hedenius, M., Persson, J., Alm, P. A., Ullman, M. T., Howard, J. H., Howard, D. V., \& Jennische, M. (2013). Impaired implicit sequence learning in children with developmental dyslexia. Research in Developmental Disabilities, 34(11), 3924-3935. https://doi.org/10.1016/j.ridd.2013.08.014

Henderson, L. M., \& Warmington, M. (2017). A sequence learning impairment in dyslexia? It depends on the task. Research in Developmental Disabilities, 60, 198-210. https://doi.org/10.1016/j.ridd.2016.11.002

Ho, C. S.-H., \& Lai, D. N.-C. (1999). Naming-speed deficits and phonological memory deficits in Chinese developmental dyslexia. Learning and Individual Differences, 11(2), 173186. https://doi.org/10.1016/S1041-6080(00)80004-7

Isbilen, E. S., McCauley, S. M., Kidd, E., \& Christiansen, M. H. (2017). Testing statistical learning implicitly: A novel chunk-based measure of statistical learning. 564-569. https://pure.mpg.de/pubman/faces/ViewItemOverviewPage.jsp?itemId=item_2503197

Just, M. A., \& Carpenter, P. A. (1992). A capacity theory of comprehension: Individual differences in working memory. Psychological Review, 99(1), 122-149. https://doi.org/10.1037/0033-295X.99.1.122

Kahta, S., \& Schiff, R. (2016). Implicit learning deficits among adults with developmental dyslexia. Annals of Dyslexia, 66(2), 235-250. https://doi.org/10.1007/s11881-016-0121-7

Kahta, S., \& Schiff, R. (2019). Deficits in statistical learning of auditory sequences among adults with dyslexia. Dyslexia, 25(2), 142-157. https://doi.org/10.1002/dys.1618 
Kelly, S. W., Griffiths, S., \& Frith, U. (2002). Evidence for implicit sequence learning in dyslexia. Dyslexia (Chichester, England), 8(1), 43-52. https://doi.org/10.1002/dys.208

Kidd, E. (2012). Implicit statistical learning is directly associated with the acquisition of syntax. Developmental Psychology, 48(1), 171-184. https://doi.org/10.1037/a0025405

Kidd, E., \& Arciuli, J. (2016). Individual Differences in Statistical Learning Predict Children's Comprehension of Syntax. Child Development, 87(1), 184-193. https://doi.org/10.1111/cdev.12461

Kuppen, S. E. A., \& Goswami, U. (2016). Developmental trajectories for children with dyslexia and low IQ poor readers. Developmental Psychology, 52(5), 717-734. https://doi.org/10.1037/a0040207

Landerl, K., Ramus, F., Moll, K., Lyytinen, H., Leppänen, P. H. T., Lohvansuu, K., O’Donovan, M., Williams, J., Bartling, J., Bruder, J., Kunze, S., Neuhoff, N., Tóth, D., Honbolygó, F., Csépe, V., Bogliotti, C., Iannuzzi, S., Chaix, Y., Démonet, J.-F., ... Schulte-Körne, G. (2013). Predictors of developmental dyslexia in European orthographies with varying complexity: Cross-linguistic predictors of dyslexia. Journal of Child Psychology and Psychiatry, 54(6), 686-694. https://doi.org/10.1111/jcpp.12029

Landerl, K., Wimmer, H., \& Frith, U. (1997). The impact of orthographic consistency on dyslexia: A German-English comparison. Cognition, 63(3), 315-334. https://doi.org/10.1016/S0010-0277(97)00005-X

Lany, J., Shoaib, A., Thompson, A., \& Estes, K. G. (2018). Infant statistical-learning ability is related to real-time language processing. Journal of Child Language, 45(2), 368-391. https://doi.org/10.1017/S0305000917000253

Long, D. L., \& Freed, E. M. (2021). An Individual Differences Examination of the Relation 
between Reading Processes and Comprehension. Scientific Studies of Reading, 25(2), 104-122. https://doi.org/10.1080/10888438.2020.1748633

Lukács, Á., Kas, B., Takács, J., \& Vidnyánszky, Z. (2021). Olvasási képességeket mérő feladatcsomag középiskolások és felnőttek számára [Test battery for examining reading abilities in adolescents and adults]. Manuscript in preparation.

Lukics, K. S., \& Lukács, Á. (2021). Tracking statistical learning online: Word segmentation in a target detection task. Acta Psychologica, 215, 103271. https://doi.org/10.1016/j.actpsy.2021.103271

Lum, J., Ullman, M., \& Conti-Ramsden, G. (2013). Procedural learning is impaired in dyslexia: Evidence from a meta-analysis of serial reaction time studies. Research in developmental disabilities, 34, 3460-3476. https://doi.org/10.1016/j.ridd.2013.07.017

Mainela-Arnold, E., \& Evans, J. L. (2014). Do statistical segmentation abilities predict lexicalphonological and lexical-semantic abilities in children with and without SLI? Journal of Child Language, 41(2), 327-351. https://doi.org/10.1017/S0305000912000736

Miller, A. C., Keenan, J. M., Betjemann, R. S., Willcutt, E. G., Pennington, B. F., \& Olson, R. K. (2013). Reading Comprehension in Children with ADHD: Cognitive Underpinnings of the Centrality Deficit. Journal of Abnormal Child Psychology, 41(3), 473-483. https://doi.org/10.1007/s10802-012-9686-8

Misyak, J. B., \& Christiansen, M. H. (2012). Statistical Learning and Language: An Individual Differences Study. Language Learning, 62(1), 302-331. https://doi.org/10.1111/j.14679922.2010.00626.x

Morgan-Short, K., Deng, Z., Brill-Schuetz, K. A., Faretta-Stutenberg, M., Wong, P. C. M., \& Wong, F. C. K. (2015). A view of the neural representation of second language syntax 
through artificial language learning under implicit contexts of exposure. Studies in Second Language Acquisition, 37(2), 383-419.

https://doi.org/10.1017/S0272263115000030

Nally, A., Healy, O., Holloway, J., \& Lydon, H. (2018). An analysis of reading abilities in children with autism spectrum disorders. Research in Autism Spectrum Disorders, 47, 14-25. https://doi.org/10.1016/j.rasd.2017.12.002

Nicolson, R. I., \& Fawcett, A. J. (2007). Procedural learning difficulties: Reuniting the developmental disorders? Trends in Neurosciences, 30(4), 135-141. https://doi.org/10.1016/j.tins.2007.02.003

Nicolson, R. I., \& Fawcett, A. J. (2011). Dyslexia, dysgraphia, procedural learning and the cerebellum. Cortex, 47(1), 117-127. https://doi.org/10.1016/j.cortex.2009.08.016

Nigro, L., Jiménez-Fernández, G., Simpson, I. C., \& Defior, S. (2016). Implicit learning of nonlinguistic and linguistic regularities in children with dyslexia. Annals of Dyslexia, 66(2), 202-218. https://doi.org/10.1007/s11881-015-0116-9

Nissen, M. J., \& Bullemer, P. (1987). Attentional requirements of learning: Evidence from performance measures. Cognitive Psychology, 19(1), 1-32. https://doi.org/10.1016/00100285(87)90002-8

Pavlidou, E. V., Louise Kelly, M., \& Williams, J. M. (2010). Do children with developmental dyslexia have impairments in implicit learning? Dyslexia, 16(2), 143-161. https://doi.org/10.1002/dys.400

Pavlidou, E. V., \& Williams, J. M. (2014). Implicit learning and reading: Insights from typical children and children with developmental dyslexia using the artificial grammar learning (AGL) paradigm. Research in Developmental Disabilities, 35(7), 1457-1472. 
https://doi.org/10.1016/j.ridd.2014.03.040

Petersson, K.-M., Folia, V., \& Hagoort, P. (2012). What artificial grammar learning reveals about the neurobiology of syntax. Brain and Language, 120(2), 83-95. https://doi.org/10.1016/j.bandl.2010.08.003

Qi, Z., S., Y., Georgan, W., G., J., \& Arciuli, J. (2018). Hearing Matters More Than Seeing: A Cross- Modality Study of Statistical Learning and Reading Ability. Scientific Studies of Reading., 23(1), 101-115. https://doi.org/10.1080/10888438.2018.1485680

Qi, Z., Sanchez Araujo, Y., Georgan, W. C., Gabrieli, J. D. E., \& Arciuli, J. (2019). Hearing Matters More Than Seeing: A Cross-Modality Study of Statistical Learning and Reading Ability. Scientific Studies of Reading, 23(1), 101-115.

https://doi.org/10.1080/10888438.2018.1485680

Racsmány, M., Lukács, Á., Németh, D., \& Pléh, C. (2005). A verbális munkamemória magyar nyelvü vizsgálóeljárásai. Magyar Pszichológiai Szemle, 60(4), 479-506. https://doi.org/10.1556/mpszle.60.2005.4.3

Ramus, F. (2003). Developmental dyslexia: Specific phonological deficit or general sensorimotor dysfunction? Current Opinion in Neurobiology, 13(2), 212-218.

Ramus, F., Rosen, S., Dakin, S. C., Day, B. L., Castellote, J. M., White, S., \& Frith, U. (2003). Theories of developmental dyslexia: Insights from a multiple case study of dyslexic adults. Brain: A Journal of Neurology, 126(Pt 4), 841-865. https://doi.org/10.1093/brain/awg076

Re, A. M., Tressoldi, P. E., Cornoldi, C., \& Lucangeli, D. (2011). Which Tasks Best Discriminate between Dyslexic University Students and Controls in a Transparent Language?: Dyslexia in University Students. Dyslexia, 17(3), 227-241. 
https://doi.org/10.1002/dys.431

Romberg, A. R., \& Saffran, J. R. (2010). Statistical learning and language acquisition. Wiley Interdisciplinary Reviews: Cognitive Science, 1(6), 906-914. https://doi.org/10.1002/wcs.78

Saffran, J. R. (2002). Constraints on Statistical Language Learning. Journal of Memory and Language, 47(1), 172-196. https://doi.org/10.1006/jmla.2001.2839

Saffran, J. R., Johnson, E. K., Aslin, R. N., \& Newport, E. L. (1999). Statistical learning of tone sequences by human infants and adults. Cognition, 70(1), 27-52. https://doi.org/10.1016/S0010-0277(98)00075-4

Saffran, J. R., Newport, E. L., \& Aslin, R. N. (1996). Word Segmentation: The Role of Distributional Cues. Journal of Memory and Language, 35(4), 606-621. https://doi.org/10.1006/jmla.1996.0032

Schmalz, X., Altoè, G., \& Mulatti, C. (2017). Statistical learning and dyslexia: A systematic review. Annals of Dyslexia, 67(2), 147-162. https://doi.org/10.1007/s11881-016-0136-0

Schubert, T. M., Cohen, T., \& Fischer-Baum, S. (2020). Reading the written language environment: Learning orthographic structure from statistical regularities. Journal of Memory and Language, 114, 104148. https://doi.org/10.1016/j.jml.2020.104148

Shaywitz, S. E., \& Shaywitz, B. A. (2007). The Neurobiology of Reading and Dyslexia. The ASHA Leader, 12(12), 20-21. https://doi.org/10.1044/leader.FTR7.12122007.20

Siegelman, N., Bogaerts, L., \& Frost, R. (2017). Measuring individual differences in statistical learning: Current pitfalls and possible solutions. Behavior Research Methods, 49(2), 418432. https://doi.org/10.3758/s13428-016-0719-z

Siegelman, N., Rueckl, J. G., Steacy, L. M., Frost, S. J., van den Bunt, M., Zevin, J. D., 
Seidenberg, M. S., Pugh, K. R., Compton, D. L., \& Morris, R. D. (2020). Individual differences in learning the regularities between orthography, phonology and semantics predict early reading skills. Journal of Memory and Language, 114, 104145. https://doi.org/10.1016/j.jml.2020.104145

Sigurdardottir, H., Danielsdottir, H., Gudmundsdottir, M., Hjartarson, K., Thorarinsdottir, E., \& Kristjánsson, Á. (2017). Problems with visual statistical learning in developmental dyslexia. Scientific Reports, 7, 606. https://doi.org/10.1038/s41598-017-00554-5

Snowling, M. (1998). Dyslexia as a Phonological Deficit: Evidence and Implications. Child and Adolescent Mental Health, 3(1), 4-11. https://doi.org/10.1111/1475-3588.00201

Snowling, M. J., \& Melby-Lervåg, M. (2016). Oral language deficits in familial dyslexia: A meta-analysis and review. Psychological Bulletin, 142(5), 498-545. https://doi.org/10.1037/bul0000037

Spencer, M., Kaschak, M. P., Jones, J. L., \& Lonigan, C. J. (2015). Statistical learning is related to early literacy-related skills. Reading and Writing, 28(4), 467-490. https://doi.org/10.1007/s11145-014-9533-0

Stanovich, K. E. (1988). The right and wrong places to look for the cognitive locus of reading disability. Annals of Dyslexia, 38(1), 154-177. https://doi.org/10.1007/BF02648254

Steacy, L. M., Wade-Woolley, L., Rueckl, J. G., Pugh, K. R., Elliott, J. D., \& Compton, D. L. (2019). The Role of Set for Variability in Irregular Word Reading: Word and Child Predictors in Typically Developing Readers and Students At-Risk for Reading Disabilities. Scientific Studies of Reading, 23(6), 523-532. https://doi.org/10.1080/10888438.2019.1620749

Stoodley, C. J., Ray, N. J., Jack, A., \& Stein, J. F. (2008). Implicit Learning in Control, Dyslexic, 
and Garden-Variety Poor Readers. Annals of the New York Academy of Sciences, 1145(1), 173-183. https://doi.org/10.1196/annals.1416.003

Stuebing, K. K., Fletcher, J. M., LeDoux, J. M., Lyon, G. R., Shaywitz, S. E., \& Shaywitz, B. A. (2002). Validity of IQ-Discrepancy Classifications of Reading Disabilities: A MetaAnalysis. American Educational Research Journal, 39(2), 469-518. https://doi.org/10.3102/00028312039002469

Swan, D., \& Goswami, U. (1997). Phonological Awareness Deficits in Developmental Dyslexia and the Phonological Representations Hypothesis. Journal of Experimental Child Psychology, 66(1), 18-41. https://doi.org/10.1006/jecp.1997.2375

Tong, X., Leung, W. W. S., \& Tong, X. (2019). Visual statistical learning and orthographic awareness in Chinese children with and without developmental dyslexia. Research in Developmental Disabilities, 92, 103443. https://doi.org/10.1016/j.ridd.2019.103443

Torkildsen, J. von K., Arciuli, J., \& Wie, O. B. (2019). Individual differences in statistical learning predict children's reading ability in a semi-transparent orthography. Learning and Individual Differences, 69, 60-68. https://doi.org/10.1016/j.lindif.2018.11.003

Vakil, E., Lowe, M., \& Goldfus, C. (2015). Performance of Children With Developmental Dyslexia on Two Skill Learning Tasks - Serial Reaction Time and Tower of Hanoi Puzzle: A Test of the Specific Procedural Learning Difficulties Theory. Journal of Learning Disabilities, 48(5), 471-481.

van den Bunt, M. R., Groen, M. A., van der Kleij, S. W., Noordenbos, M. W., Segers, E., Pugh, K. R., \& Verhoeven, L. (2018). Deficient Response to Altered Auditory Feedback in Dyslexia. Developmental Neuropsychology, 43(7), 622-641. https://doi.org/10.1080/87565641.2018.1495723 
van Witteloostuijn, M., Boersma, P., Wijnen, F., \& Rispens, J. (2017). Visual artificial grammar learning in dyslexia: A meta-analysis. Research in Developmental Disabilities, 70, 126137. https://doi.org/10.1016/j.ridd.2017.09.006 van Witteloostuijn, M., Boersma, P., Wijnen, F., \& Rispens, J. (2019). Statistical learning abilities of children with dyslexia across three experimental paradigms. PLOS ONE, 14(8), e0220041. https://doi.org/10.1371/journal.pone.0220041

Vellutino, F. R., Fletcher, J. M., Snowling, M. J., \& Scanlon, D. M. (2004). Specific reading disability (dyslexia): What have we learned in the past four decades? Journal of Child Psychology and Psychiatry, 45(1), 2-40. https://doi.org/10.1046/j.00219630.2003.00305.x

Vicari, S., Marotta, L., Menghini, D., Molinari, M., \& Petrosini, L. (2003). Implicit learning deficit in children with developmental dyslexia. Neuropsychologia, 41(1), 108-114. https://doi.org/10.1016/s0028-3932(02)00082-9

Waters, G. S., \& Caplan, D. (1996). The Measurement of Verbal Working Memory Capacity and Its Relation to Reading Comprehension. The Quarterly Journal of Experimental Psychology Section A, 49(1), 51-79. https://doi.org/10.1080/713755607

Wimmer, H., \& Mayringer, H. (2002). Dysfluent reading in the absence of spelling difficulties: A specific disability in regular orthographies. Journal of Educational Psychology, 94(2), 272-277. https://doi.org/10.1037/0022-0663.94.2.272

Wolf, M., \& Bowers, P. G. (1999). The double-deficit hypothesis for the developmental dyslexias. Journal of Educational Psychology, 91(3), 415-438. https://doi.org/10.1037/0022-0663.91.3.415 